\title{
Reductions in midbrain GABAergic and dopamine neuron markers are linked in schizophrenia
}

Tertia D. Purves-Tyson ${ }^{1,2^{*}} \mathbb{D}$, Amelia M. Brown ${ }^{1 \dagger}{ }^{\dagger}$ Christin Weissleder ${ }^{1}$, Debora A. Rothmond ${ }^{1}$ and

Cynthia Shannon Weickert ${ }^{1,2,3^{*}}$ (1)

\begin{abstract}
Reductions in the GABAergic neurotransmitter system exist across multiple brain regions in schizophrenia and encompass both pre- and postsynaptic components. While reduced midbrain GABAergic inhibitory neurotransmission may contribute to the hyperdopaminergia thought to underpin psychosis in schizophrenia, molecular changes consistent with this have not been reported. We hypothesised that reduced GABA-related molecular markers would be found in the midbrain of people with schizophrenia and that these would correlate with dopaminergic molecular changes. We hypothesised that downregulation of inhibitory neuron markers would be exacerbated in schizophrenia cases with high levels of neuroinflammation. Eight GABAergic-related transcripts were measured with quantitative PCR, and glutamate decarboxylase (GAD) 65/67 and GABA alpha 3 (a3) (GABRA3) protein were measured with immunoblotting, in post-mortem midbrain (28/28 and 28/26 control/schizophrenia cases for mRNA and protein, respectively), and analysed by both diagnosis and inflammatory subgroups (as previously defined by higher levels of four pro-inflammatory cytokine transcripts). We found reductions (21 - 44\%) in mRNA encoding both presynaptic and postsynaptic proteins, vesicular GABA transporter (VGAT), GAD1, and parvalbumin (PV) mRNAs and four alpha subunits $(a 1, a 2, a 3, a 5)$ of the $G_{A B A}$ receptor in people with schizophrenia compared to controls $(p<0.05)$. Gene expression of somatostatin (SST) was unchanged $(p=0.485)$. We confirmed the reduction in GAD at the protein level (34\%, $p<0.05)$. When stratifying by inflammation, only GABRA3 mRNA exhibited more pronounced changes in high compared to low inflammatory subgroups in schizophrenia. GABRA3 protein was expressed by $98 \%$ of tyrosine hydroxylase-positive neurons and was $23 \%$ lower in schizophrenia, though this did not reach statistical significance $(p>0.05)$. Expression of transcripts for $\mathrm{GABA}_{\mathrm{A}}$ receptor alpha subunits 2 and 3 (GABRA2, GABRA3) were positively correlated with tyrosine hydroxylase (TH) and dopamine transporter (DAT) transcripts in schizophrenia cases (GABRA2; $r>0.630$, GABRA3; $r>0.762$, all $p<0.001$ ) but not controls (GABRA2; $r<-0.200$, GABRA3; $r<0.310$, all $p>0.05$ ). Taken together, our results support a profound disruption to inhibitory neurotransmission in the substantia nigra regardless of inflammatory status, which provides a potential mechanism for disinhibition of nigrostriatal dopamine neurotransmission.
\end{abstract}

Keywords: GABA, GABRA, GAD1, GAD65/67, Parvalbumin, Somatostatin, Tyrosine hydroxylase, Substantia nigra, Schizophrenia, Neuroinflammation

*Correspondence: t.purves-tyson@neura.edu.au; cyndi@neura.edu.au ${ }^{\dagger}$ Tertia D. Purves-Tyson and Amelia M. Brown joint first authors 1 Schizophrenia Research Laboratory, Neuroscience Research Australia, 139 Barker Street, Margarete Ainsworth Building, Level 5, Randwick, NSW 2031, Australia

Full list of author information is available at the end of the article

\section{Introduction}

Dopamine (DA) dysregulation, which can be traced to a common neural origin in the midbrain, manifests in striatal hyperdopaminergia, which is linked to psychosis, and cortical hypodopaminergia, which contributes 
to cognitive deficits [1, 2]. Importantly, gamma aminobutyric acid (GABA) neurotransmission controls activity of dopamine neurons within the midbrain [3-6], yet the status of the midbrain GABA neurons has not been thoroughly examined in schizophrenia. Among the most consistently replicated neurobiological changes in schizophrenia is a reduction in GABAergic transmitter system markers. Reductions in gene and protein expression of GABAergic inhibitory interneuron markers and other GABA-related molecules in schizophrenia are demonstrated across multiple brain regions, including cortex, hippocampus, striatum and cerebellum, pointing to widespread deficits in inhibitory neurotransmission [7-11]. Thus, we sought to determine whether deficits in inhibitory neurotransmission extend to the midbrain in schizophrenia.

Within the midbrain, the substantia nigra (SN) is the origin of the dopaminergic nigrostriatal projections to the dorsal striatum. The dorsal striatum [12-14] and the SN [1, 2, 14-18] are identified as major loci of dopamine dysregulation in schizophrenia. We have previously reported dysregulation of multiple DA-related mRNAs in the midbrain in schizophrenia, including lower gene expression of DA receptor D2 isoforms (DRD2short, and DRD2long), DA transporter (DAT), vesicular monoamine transporter (VMAT), and a synthesis enzyme (aromatic acid decarboxylase) [17]. The SN consists of the predominantly dopaminergic pars compacta (SNpc), and the predominantly GABAergic pars reticulata (SNpr) $[19,20]$. $\mathrm{SNpc}$ dopamine neurons receive excitatory input from the cortex and thalamus, and inhibitory input both from GABAergic projection neurons in the striatum and $\mathrm{SNpr}$, and interneurons in the SNpc [21]. A loss of GABAergic inhibitory control at the site of origin of dopamine neurons may lead to increased dopamine activity [22]. Here, we sought to test if molecular deficiencies in GABAergic inhibitory interneurons occur in the midbrain of people with schizophrenia.

GABAergic neurons are identified by expression of the GABA synthesising enzyme glutamate decarboxylase (GAD) isoforms, GAD67 (GAD1) and GAD65 (GAD2), expressed by all interneuron subtypes [23, 24]. A reduction in cortical GAD67 mRNA and protein is consistently demonstrated in schizophrenia [25-29]. However, contrary to our prediction of a deficit in inhibition, a single study reports elevated GAD67 protein in the midbrain in schizophrenia [30]. Changes in GAD are often, but not always [31], accompanied by alterations in vesicular GABA transporter (VGAT) [27, 32] and in other inhibitory interneuron markers. GABAergic inhibitory interneuron subtypes are identified by expression of neuropeptides and calcium-binding proteins [33-35]. In schizophrenia, gene and protein expression of interneuron markers, particularly parvalbumin (PV) and somatostatin (SST), are often reduced in the cortex [7, 28, 32, 36-39], cerebellum [9, 10], and hippocampus [8]. Interestingly, PV + cells found within the $\mathrm{SN}$ are not morphologically consistent with interneurons [34], rather local inhibitory control in the $\mathrm{SN}$ is from axon collaterals of PV-expressing projection neurons that have their cell bodies in the SNpr and project axons to the thalamus or superior colliculus [3, 21, 34, 40,41]. Branches of these axons synapse directly onto the dopaminergic neurons of the SNpc [42, 43]. Within the SNpc, 30\% of neurons express GAD1 mRNA [44], and immunohistochemical and in situ hybridisation studies have identified SSTpositive neurons in the midbrain $[45,46]$. It is unknown whether there are molecular changes in GAD1, $P V$ and SST transcripts in the midbrain in schizophrenia.

Neuroinflammation is implicated in the pathophysiology of schizophrenia and is linked to inhibitory interneuron deficits in the cortex [47-53]. We recently identified heightened neuroinflammation in the midbrain of people with schizophrenia $[54,55]$. Gene expression of inflammatory markers, particularly IL1B, IL6, SERPINA3 (and TNFA in midbrain), are used to identify schizophrenia cases with 'low' and 'high' inflammatory biotypes [50, 51, $54,56,57]$. In the cortex, schizophrenia cases with a high inflammatory biotype have lower GAD1, SST, and $P V$ mRNAs when compared to schizophrenia cases with the low inflammatory biotype [50]. Furthermore, increased gene expression of the viral restriction factor interferoninduced transmembrane protein (IFITM) is linked to lower expression of GABA-related mRNAs, including GAD1 and SST, in the cortex of schizophrenia cases [53]. We therefore hypothesised that changes in GABA synthesis and interneuron marker gene expression would be exacerbated in the midbrain of schizophrenia cases with a high inflammatory biotype.

Regulation of GABAergic neurotransmission also occurs at the level of postsynaptic receptors and alterations in $\mathrm{GABA}_{\mathrm{A}}$ subunits are identified in schizophrenia $[58,59]$. The ionotropic $\mathrm{GABA}_{\mathrm{A}}$ receptor has multiple subunits that differ both functionally and in their regional specificity $[60,61]$. In the $\mathrm{SN}$, the $\alpha 1$ subunit is expressed almost exclusively in the $\mathrm{SNpr}$, and $\alpha 2$ and $\alpha 5$ are expressed in both the $\mathrm{SNpc}$ and $\mathrm{SNpr}$, albeit at relatively low levels [62-69]. $\mathrm{GABA}_{\mathrm{A}}$ receptors that express the $\alpha 3$ subunit are highly expressed on dopaminergic neurons of the SNpc [63, 64, 69], though, to our knowledge, this subunit has not been explored in schizophrenia. In schizophrenia, gene expression of $\mathrm{GABA}_{\mathrm{A}}$ receptor alpha subunits one $(\alpha 1)$, two $(\alpha 2)$, and five $(\alpha 5)$ are altered in dorsolateral prefrontal cortex and hippocampus [7, 8, 25], but the levels of these subunit mRNAs are unexplored in the midbrain. We hypothesised that transcripts encoding 
the alpha subunits of the $\mathrm{GABA}_{\mathrm{A}}$ receptors would be expressed at lower levels in the midbrain in schizophrenia and that these reductions would be exacerbated in schizophrenia cases with a high inflammatory biotype.

We previously showed lower gene expression of some mRNAs encoding proteins involved in dopamine neurotransmission in the post-mortem midbrain in schizophrenia [17]. To further elucidate whether and how changes in the GABAergic system in the midbrain may contribute to dopamine dysregulation in schizophrenia, we explored the relationships between GABA- and DArelated transcripts in controls and schizophrenia cases, to identify whether these relationships are altered in the disease state.

To test our hypotheses, we sought to determine in a human midbrain cohort (28/28 and 28/26 control/schizophrenia cases for mRNA and protein, respectively), whether GAD1 mRNA and GAD protein, as well as $P V$, $S S T$ and VGAT mRNA transcripts are lower in the midbrain in schizophrenia. We sought to determine relative levels of GABRA1, GABRA2, GABRA3, and GABRA5 mRNAs, GABRA3 protein levels, and to determine cellular location of GABRA3 protein in the midbrain in schizophrenia. Furthermore, we sought to determine whether any measured alterations in GABA-related transcripts were related to a heightened state of neuroinflammation in the midbrain. We also investigated the relationships between GABA-related transcripts and DA-related transcripts.

\section{Methods}

Post-mortem midbrain tissue and cohort demographics

Midbrain tissue was sourced from the NSW Brain Tissue Resource Centre and experiments were approved by the University of New South Wales Human Research Ethics Committee (HREC \#17826). The tissue samples (30 schizophrenia, 30 controls) were dissected from $60 \mu \mathrm{m}$ cryostat sections of the midbrain cut in the coronal plane at the level of the oculomotor nerve exit. The area excised included both the SNpc and SNpr, found in the ventral mesencephalon below the red nucleus, as previously described [17]. RNA was extracted from six $60 \mu \mathrm{m}$ tissue sections for each case.

Cases in both the mRNA and protein cohorts were matched on age, sex, and post-mortem interval (PMI), as previously described [17] (Table 1). pH was significantly lower in schizophrenia patients compared to controls. RNA integrity number (RIN), age, and PMI did not change significantly between schizophrenia cases and control subjects (Table 1), or between inflammatory subgroup (Table 2). The average RIN of control cases was $5.56 \pm 1.15$ (range 3.0-7.3), and 5.61 \pm 1.31 (range 3.2-8.3) for schizophrenia cases (Table 1). Samples with RINs $<3.0$ were excluded from further analysis. The RIN cut-off was selected to retain as many cases as possible. Samples with lower RIN values can produce accurate data so long as this is factored into the statistical analysis (refer to Statistical Analysis) [70, 71]. We use the geometric mean of four housekeeping mRNAs as a normaliser

Table 1 Demographic details of the post-mortem midbrain mRNA and protein cohorts classified by diagnosis. Table previously published in [17,55]

\begin{tabular}{|c|c|c|c|c|c|c|}
\hline \multirow[t]{2}{*}{ Demographics } & \multicolumn{3}{|l|}{ mRNA Cohort } & \multicolumn{3}{|l|}{ Protein Cohort } \\
\hline & Control (28) & SCZ (28) & Statistics & Control (28) & SCZ (26) & Statistics \\
\hline Age (years) (range) & $50.54(22-67)$ & $51.36(26-67)$ & $\begin{array}{l}\mathrm{t}(54)=-0.27 \\
p=0.79\end{array}$ & $52.21(22-69)$ & $52.29(26-67)$ & $\begin{array}{l}\mathrm{t}(52)=-0.23 \\
p=0.82\end{array}$ \\
\hline $\operatorname{Sex}(M, F)$ & $(20,8)$ & $(19,9)$ & $\begin{array}{l}X^{2}(1,56)=0.084 \\
p=0.771\end{array}$ & $(19,9)$ & $(16,10)$ & $\begin{array}{l}X^{2}(1,54)=0.236, \\
p=0.627\end{array}$ \\
\hline $\mathrm{pH}$ & $6.66 \pm 0.26$ & $6.51 \pm 0.20$ & $\begin{array}{c}t(54)=2.52 \\
p=0.015^{*}\end{array}$ & $6.69 \pm 0.24$ & $6.51 \pm 0.23$ & $\begin{array}{c}t(52)=2.62 \\
p=0.011^{*}\end{array}$ \\
\hline PMI (hours) (range) & $\begin{array}{l}31.68 \pm 10.21 \\
(15-50)\end{array}$ & $35.66 \pm 17.71(5-72)$ & $\begin{array}{l}t(54)=-1.03 \\
p=0.31\end{array}$ & $32.75 \pm 9.90(15-50)$ & $38.21 \pm 18.20(5-72)$ & $\begin{array}{l}t(52)=-1.38 \\
p=0.17\end{array}$ \\
\hline RIN (range) & $5.56 \pm 1.15(3.0-7.3)$ & $5.61 \pm 1.31(3.2-8.3)$ & $\begin{array}{l}t(54)=-0.15 \\
p=0.88\end{array}$ & - & - & - \\
\hline Duration of illness & - & $28.31 \pm 12.72(4-49)$ & - & - & $29.12 \pm 13.02(4-49)$ & - \\
\hline Daily CPZ (mg) & - & $736.45 \pm 520.50$ & - & - & $716.37 \pm 557.76$ & - \\
\hline $\begin{array}{l}\text { Last recorded CPZ } \\
\quad(\mathrm{mg})\end{array}$ & - & $597.54 \pm 497.64$ & - & - & $616.20 \pm 506.60$ & - \\
\hline Lifetime CPZ (g) & - & $8231.44 \pm 8714.24$ & - & - & $8427.92 \pm 9348.47$ & - \\
\hline
\end{tabular}

Bold text indicates statistically significant data

F female, $M$ male, $P M I$ post-mortem interval, RIN RNA integrity, SCZ schizophrenia, CPZ chlorpromazine equivalent

Data are mean \pm s.d. Age and PMI ranges are in brackets. Note the group sizes are different in the cohorts as different cases were excluded with either poor quality of RNA and/or protein. A schizophrenia case in this mRNA cohort was lost from the mRNA cohort published previously [17] due to failure of cDNA synthesis

${ }^{*} p<0.05$ 


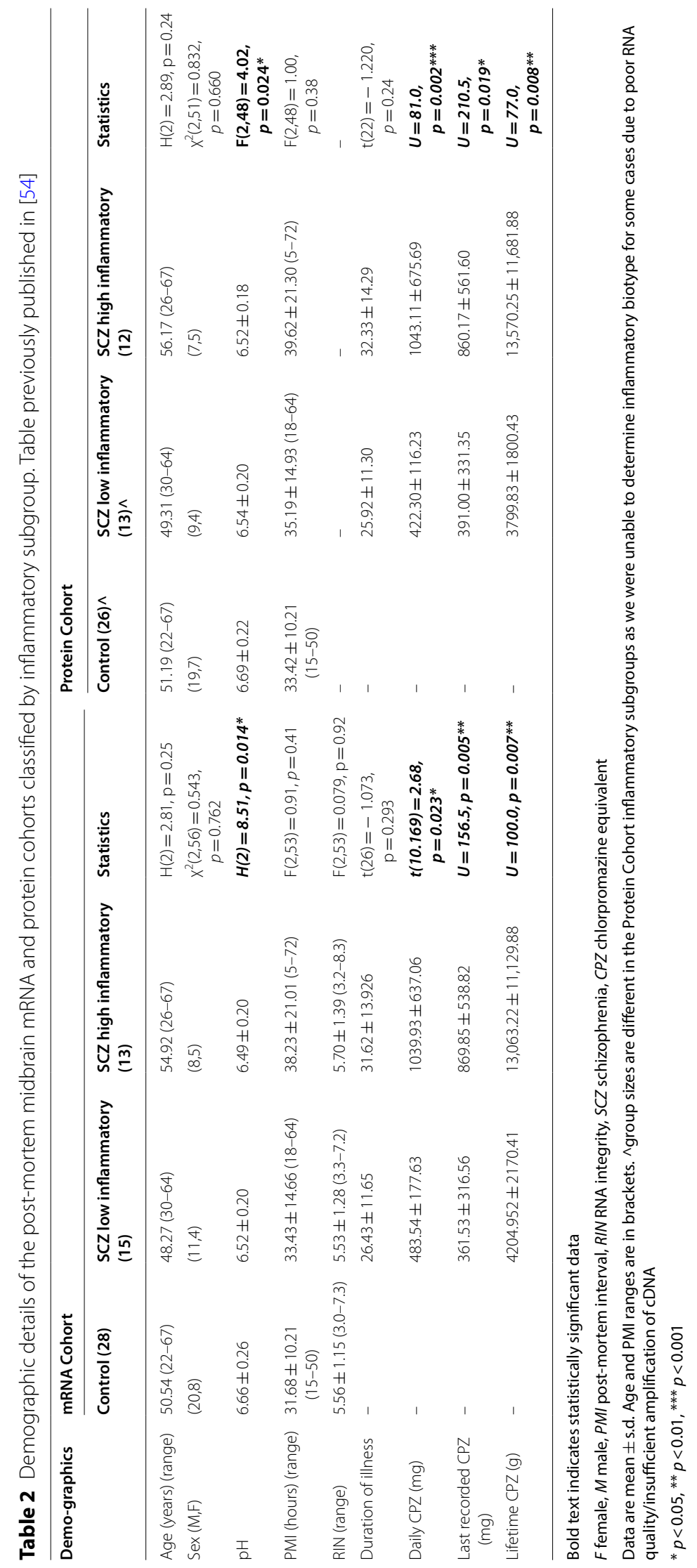


for our genes of interest to account for any degradation of transcripts at different levels of mRNA abundance, and this denominator serves as an index of RNA degradation and is accounted for in our analysis [72]. The final midbrain mRNA cohort comprised 28 schizophrenia cases and 28 controls as 3 cases ( 1 control, 2 schizophrenia) were excluded due to RINs $<3.0$, and 1 control case due to insufficient cDNA amplification. The final protein cohort consisted of 26 schizophrenia cases and 28 controls. This midbrain mRNA cohort has previously been divided into low and high inflammatory biotype, as determined through a recursive two-step cluster analysis of gene expression of SERPINA3, IL6, IL1B, and TNFA (detailed in [54]). No control cases had a high inflammatory biotype, whilst 13 schizophrenia cases had a high inflammatory biotype, and the remaining 15 were classified with a low inflammatory biotype (Table 2) [54]. The cases retained in the mRNA and protein cohorts do not completely overlap, as $2-4$ different cases per group were excluded from each cohort due to poor quality protein and/or mRNA/cDNA amplification. In addition, not all cases included in the protein cohort have an assigned inflammatory biotype due to poor RNA/insufficient cDNA amplification.

All schizophrenia cases were treated with antipsychotics, the calculated doses of which were standardised, as previously described [17], to a chlorpromazine equivalent (CPZ) incorporating measures of lifetime, daily dosage, and last dosage. Other ante-mortem factors, including illness duration, smoking (lifetime and at time of death), the nature of symptoms (positive or negative, and depressive), agonal state, and suicide as the cause of death, were recorded. Additional information about freezer storage time, antipsychotic types, alcohol use, toxicology screening, alcohol consumption and history of depression are included in Additional file 1.

\section{RNA extraction and quantitative real-time PCR}

Total RNA was extracted from midbrain samples using TRIzol (Invitrogen, Mulgrave, VIC, AUS). Tissue was homogenised in $800 \mu \mathrm{l}$ of TRIzol using a disposable tissue pestle (Axygen, Mount Martha, VIC, Australia) and incubated at room temperature for $5 \mathrm{~min}$. Chloroform $(160 \mu \mathrm{L})$ was added, and the mixture was vortexed, then centrifuged for $15 \mathrm{~min}\left(12,000 \mathrm{~g}\right.$ at $\left.4{ }^{\circ} \mathrm{C}\right)$. The aqueous phase was transferred to a new tube. $400 \mu$ l of isopropanol was added and incubated for $10 \mathrm{~min}$, and the mixture spun for $10 \mathrm{~min}\left(12,000 \mathrm{~g}\right.$ at $\left.4{ }^{\circ} \mathrm{C}\right)$. Isopropanol was removed, and the pellet was washed in $800 \mu \mathrm{L}$ of $70 \%$ ethanol, and then centrifuged for $5 \mathrm{~min}\left(7500 \mathrm{~g}\right.$ at $\left.4{ }^{\circ} \mathrm{C}\right)$. Ethanol was removed; samples were air-dried and resuspended in $30 \mu \mathrm{l}$ RNAse-free water (Sigma-Aldrich, Castle Hill, NSW, AUS). RNA was quantified by nanodrop using a ND-1000 Spectrophotometer (Nanodrop Technologies, Wilmington, DE, USA). RNA integrity number (RIN) was measured for each sample using Agilent Bioanalyzer 2100 (Agilent Technologies, Santa Clara, CA, USA). Complementary DNA (cDNA) was generated using Superscript IV First Strand Synthesis Kit and random hexamers (18091200; Invitrogen) according to the manufacturer's protocol.

TaqMan gene expression assays (Invitrogen) (Additional file 1: Table S1) were used to run high-throughput qPCR (Fluidigm; Ramaciotti Centre for Genomics, UNSW, Sydney) for seven genes, and a single qPCR for GABRA3 was run on an Applied Biosystems Prism 7900 HT Fast Real Time system. In addition, we remeasured tyrosine hydroxylase $(T H)$ and $D A T$ mRNAs using the same TaqMan gene expression assays as previously [17] but with the high-throughput Fluidigm qPCR method. PCR cycling conditions were $50{ }^{\circ} \mathrm{C}$ for $2 \mathrm{~min}$, $95{ }^{\circ} \mathrm{C}$ for $10 \mathrm{~min}$, then 50 cycles of $95^{\circ} \mathrm{C}$ for $15 \mathrm{~s}$ and $60{ }^{\circ} \mathrm{C}$ for $1 \mathrm{~min}$. Samples in the single qPCR were run in triplicate, samples measured by Fluidigm were run in singulate. Serial dilutions of pooled cDNA from all samples were used to quantitate sample expression by the relative standard curve method. To confirm replicability between the qPCR methods, and the use of triplicates or singulates, we show that relative gene expression of DAT and $\beta$-actin measured using both methods are highly significantly positively correlated (DAT mRNA, $\mathrm{N}=53$, $\mathrm{R}^{2}=0.893, p<0.0001 ; \beta$-actin mRNA, $\mathrm{N}=55, \mathrm{R}^{2}=0.680$, $p<0.0001)$.

Gene expression of eight GABAergic markers was measured: GAD1, PV, SST, VGAT, GABRA1, GABRA2, GABRA3, and GABRA5. Gene expression data was analysed with Fluidigm Real-Time PCR Analysis software (version 4.5.2), or SDS software (version 2.4; ABI, Life Technologies). Gene expression was normalised to the geomean of four housekeeping genes measured by highthroughput qPCR: $\beta$-actin, TATA-box binding protein, ubiquitin-C, and glyceraldehyde 3-phosphate dehydrogenase. No differences were found either between the expression of housekeeping genes by diagnosis, nor in the geomean across experimental groups (all $\mathrm{t}<1.160$, $\mathrm{df}=53-54, p>0.05)$. Gene expression data are presented as relative mRNA levels \pm SEM.

\section{Western blotting}

Protein was extracted as previously described [17]. In brief, samples were homogenised in $0.1 \mathrm{M}$ Tris ( $\mathrm{pH} 7.5$ ), $50 \%$ glycerol, protease inhibitor cocktail and aprotinin $(0.015 \mathrm{mM})$ (all Sigma-Aldrich) with a handheld electric homogeniser (Polytron, Kinematica, Lucerne, Switzerland). Protein was quantified using a Bradford protein assay (B6916, Sigma-Aldrich). For each case, $5 \mu \mathrm{g}$ (for 
GAD) and $6 \mu \mathrm{g}$ (for GABRA3) protein was diluted in NuPAGE Sample Buffer (NP0007) and NuPAGE Sample Reducing Agent (NP0009) and separated on a NuPAGE Tris-Acetate 3-8\% gel (WG1603A). Samples were run alongside Precision Plus Protein Standard (Biorad, Gladesville, NSW, AUS, \#161-0374) and an internal control (IC) comprised of randomly selected samples pooled from within the cohort $(70 \mathrm{~min}, 150 \mathrm{~V})$. Three gels were required to run the full midbrain cohort and each gel had an IC to allow comparison between immunoblots. Samples were distributed randomly across the three gels. Proteins were transferred onto nitrocellulose membranes with the Power Blotter System (PB0012; all reagents Invitrogen). Membranes were rinsed in trisbuffered saline with Tween-20 (TBST) and blocked for $2 \mathrm{~h}$ in $5 \%$ skim milk in TBST. GAD protein was detected with a rabbit anti-glutamate decarboxylase 65/67 antibody (1:1000, AB1511, Sigma-Aldrich), previously used to show expected and specific expression in the cell bodies and processes of interstitial white matter neurons in the cortex [73], and GABRA3 protein with rabbit antiGABA Receptor $\alpha 3$ antibody (1:1000, ab224214, Abcam, Melbourne, VIC, AUS). Primary antibodies were diluted in $1 \%$ skim milk in TBST and incubated overnight at $4{ }^{\circ} \mathrm{C}$. Membranes were rinsed with TBST and incubated with a horseradish peroxidase-conjugated (HRP) secondary antibody (1:5000, AP307P, Merck-Millipore, Bayswater, VIC, AUS) for $1 \mathrm{~h}$ at room temperature. Membranes were rinsed and re-probed with mouse anti- $\beta$-actin antibody (1:5000, MAB1501, Merck-Millipore), incubated at room temperature for at least $2 \mathrm{~h}$, then incubated with HRPconjugated goat anti-mouse secondary antibody for $1 \mathrm{~h}$ (1:5000, AP124P, Merck-Millipore). Full Western blots are presented in Additional file 1: Fig. S2. The GABRA3 Western blot shown was stripped with $2 \times 15$ min washes in $0.025 \mathrm{M}$ glycine, $1.5 \%$ SDS buffer prior to being reblocked and re-probed with the $\beta$-actin secondary antibody. The GAD Western Blot shown was not stripped.

Protein bands were visualised with high-sensitivity enhanced chemiluminescent substrate (WBKLS0100, Merck-Millipore), and imaged on the iBright 1500 Imaging System (Invitrogen) to provide a density measurement for each band. For GAD65/67, a single band was detected at $\sim 66 \mathrm{kDa}$. A prominent $\sim 55 \mathrm{kDa}$ band was detected for GABRA3. On each separate Western blot, for the IC, the band density of the protein of interest was divided by the band density of $\beta$-actin to generate a normalised IC value for each blot. Each sample on the Western blot was then divided by this value such that the normalised IC value on each separate Western blot is equivalent to 1 and band densities of samples can then be compared across multiple Western blots in a single experiment. As such, the band density of the protein of interest for each sample was divided by the density of the $\sim 42 \mathrm{kDa} \beta$-actin band for the same sample (to give a normalised value), and this value was divided by the normalised IC value for that immunoblot to give a measure of relative protein expression. The band density of $\beta$-actin did not differ according to diagnosis $[\mathrm{t}(46-53)<0.4782$, $\mathrm{p}>0.635]$.

\section{Immunohistochemistry}

Double-label immunofluorescence for GABRA3 and TH was performed to confirm GABRA3 expression by dopaminergic neurons using $14 \mu \mathrm{m}$ fresh frozen midbrain tissue sections from 3 control and 3 high inflammatory schizophrenia cases. Sections were fixed in 4\% PFA (Sigma-Aldrich) $\left(10 \mathrm{~min}, 4{ }^{\circ} \mathrm{C}\right)$ and blocked for $1 \mathrm{~h}$ in $10 \%$ normal donkey serum (Millipore-Merck), 0.3\% Triton X-100 (Sigma-Aldrich) and 0.05\% BSA in PBS for $1 \mathrm{~h}$. Slides were incubated overnight at $4{ }^{\circ} \mathrm{C}$ with rabbit antiGABRA3 (1:200, ab224214, Abcam) and mouse anti-TH (1:400, MAB318, Millipore-Merck) antibodies prepared in $0.3 \%$ Triton X-100 and $0.05 \%$ BSA in PBS. Slides were washed $3 \times 10 \mathrm{~min}$ in PBS and Alexa Fluor-conjugated secondary antibodies (AF594 anti-rabbit; AF488 antimouse, both 1:500, Life Technologies, AUS) were added for $1 \mathrm{~h}$ at room temperature. To minimise auto-fluorescence, slides were washed in $15 \mathrm{mM}$ cupric sulphate (Sigma-Aldrich) and $50 \mathrm{mM}$ ammonium acetate (SigmaAldrich) for $2 \times 15 \mathrm{~min}$ [74]. Slides were counterstained with DAPI (1:1000, Sigma-Aldrich) in PBS and coverslipped with anti-fade mounting media (Citifluor antifadent, ProSciTech, Kirwan, QLD, Australia). A negative control slide without primary antibodies was included and did not produce any signal (Additional file 1: Fig. S1).

Images of GABRA3 and TH double-labelling immunohistochemistry were taken on a LSM800 Zeiss confocal microscope (Zeiss Australia, Lonsdale, SA, AUS), equipped with a high efficiency GaAsP detector, two multi-alkali photomultiplier tubes and the following objectives: $10 \times$ air objective with numerical aperture (NA) $0.45,20 \times$ air objective with NA 0.8 and $40 \times$ oil objective with NA 1.3. Detection wavelengths were $490-580 \mathrm{~nm}$ for AF488, 580-700 nm for AF594 and 400$580 \mathrm{~nm}$ for DAPI. For quantification of the percentage of $\mathrm{TH}^{+}$neurons expressing GABRA3, three $\mathrm{z}$-stacks of each case were acquired using the $10 \times$ air objective [ $0.7 \mathrm{zoom}$, average thickness $\mu \mathrm{m} \pm$ standard deviation (range): $13.80 \pm 2.60$ (10.62-19.47)]. Maximum intensity projections were used to visualise the brightest voxel in the final image. $\mathrm{TH}^{+}$neurons with abundant immunostaining in the soma were counted $\left(75 \pm 30\right.$ per case, 451 total $\mathrm{TH}^{+}$ neurons) and the percentage of $\mathrm{TH}^{+}$cells co-expressing GABRA3 was determined. Additional z-stacks were acquired using the $20 \times$ air and $40 \times$ oil objectives 
[average thickness $\mu \mathrm{m} \pm$ standard deviation (range): $8.12 \pm 3.38$ (5.2-12.96)]. Image analysis and quantification were conducted using Zeiss Zen software version 3.1 (blue edition, Zeiss, Australia) and ImageJ version 1.50e (NIH, Bethesda, MD, USA).

\section{Statistical Analysis}

SPSS was used for all statistical analysis (IBM SPSS Statistics, version 25) and significance was set at the level of $p<0.05$. Outliers, identified as values beyond two standard deviations of the mean, were excluded from subsequent analysis. Data for each gene or protein of interest was tested for normality using the Shapiro-Wilk test, and homogeneity of variance using Levene's test. SST, $P V$ mRNA and GAD protein did not pass Levene's test. All transcripts except GABRA1 and $P V$ were normally distributed when considered by diagnosis, when considered by diagnosis/inflammatory subgroup, all transcripts except $P V$ were normally distributed.

\section{Covariates}

For each transcript or protein of interest, the relationship to PMI, $\mathrm{pH}$, and age was assessed by Pearson's correlations (Additional file 1: Table S2). RIN was assessed as a covariate for transcripts of interest. GAD and GABRA3 protein were not correlated with PMI, $\mathrm{pH}$, or age. Variables that correlated with gene expression were incorporated as covariates in an analysis of covariance (ANCOVA). No gene expression was significantly correlated with age, and PMI was significantly correlated only with $P V$ mRNA. RIN was frequently correlated with GABAergic gene expression. Brain $\mathrm{pH}$ was correlated with gene expression of multiple GABA-related transcripts (Additional file 1: Table S2), but not used as a covariate, as lower $\mathrm{pH}$ levels are considered to be part of the disease process in schizophrenia [75], and co-varying for $\mathrm{pH}$ may inappropriately "correct" for variance due to disease.

\section{Analysis of relative gene expression by diagnosis and by diagnosis/inflammatory subgroup}

For genes and proteins of interest that were normally distributed by diagnosis, an independent samples two-tailed $t$ test was used if data was not correlated with any demographic variables. ANCOVAs were run for transcripts that correlated with demographic variables. GABRA1 and $P V$ mRNA levels could not be transformed to normality, and these variables were ranked and residualised by the rank of their covariates. GABRA1 mRNA levels were tested with a Mann-Whitney $\mathrm{U}$ test, and $P V$ mRNA with an independent samples two-tailed $t$-test $(P V$
mRNA levels were normally distributed after residualisation, whereas GABRA1 mRNA levels were not).

For analysis by diagnosis/inflammatory subgroups, data was analysed with ANOVA or ANCOVA, where appropriate. GABRA1 mRNA levels underwent a square root transformation of the inflammatory subgroups to reach normality and ranked $P V$ mRNA was residualised with ranked PMI and RIN to reach normality. Where significant effects were observed, the analysis was followed by a least significant difference (LSD) post-hoc test.

\section{Correlations between GABA- and DA-related gene expression}

Correlations between DA- and GABA-related gene expression were investigated in control and schizophrenia groups separately. The dopaminergic markers included were $T H$ and DAT mRNAs (both log transformed to normality), which were examined for correlations between each of GABRA1, GABRA2, GABRA3, and GABRA5. Pearson's correlations were run to assess covariates with age, PMI, and RIN in both the dopaminergic and GABAergic genes. If a covariate was present in either marker, partial correlations were run. To determine if correlation coefficients in control and schizophrenia groups were significantly different, they were converted to $z$ scores using Fisher's $r$-to- $z$ transformation.

\section{Analysis of pre- and ante-mortem factors and antipsychotic treatment}

The genes of interest were statistically explored to consider alterations due to clinical and ante-mortem variables. Spearman's correlations were used to explore the relationships between antipsychotic treatment measures as well as duration of illness (in years), and transcripts of interest (Additional file 1: Table S3). Age was used as a covariate in the correlation between SST mRNA and duration of illness, as SST levels decrease with age $[36,38]$. Other clinical variables measured were antipsychotic type (first-generation, second-generation, or both), clozapine use (indicative of treatment resistance), and whether the patient exhibited predominantly positive or negative symptoms (Additional file 1). Ante-mortem variables explored included lifetime smoking, and lifetime symptoms of depression, as well as variables assessed at the time of death-smoking at time of death, agonal state, and suicide (Additional file 1). Clinical variables were assessed with independent samples two-tailed $t$ tests or one-way ANOVA. Suicide was only reported as the cause of death for some schizophrenia cases and no controls and was assessed by independent samples two-tailed $t$ tests. All other variables were assessed by two-way ANOVA with diagnosis and the variable of interest as independent variables. Results are considered 
a.

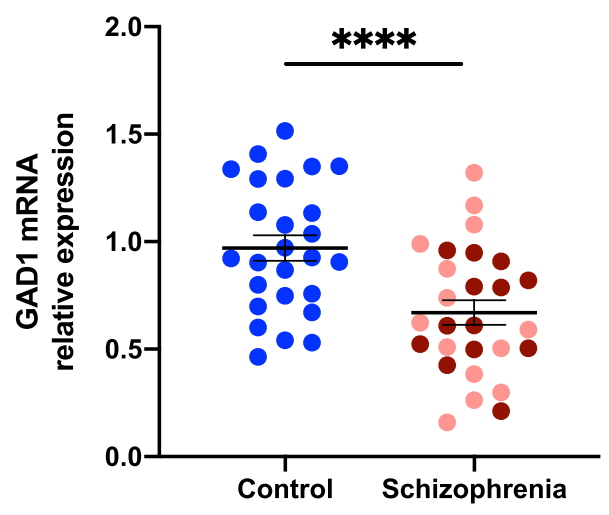

b.

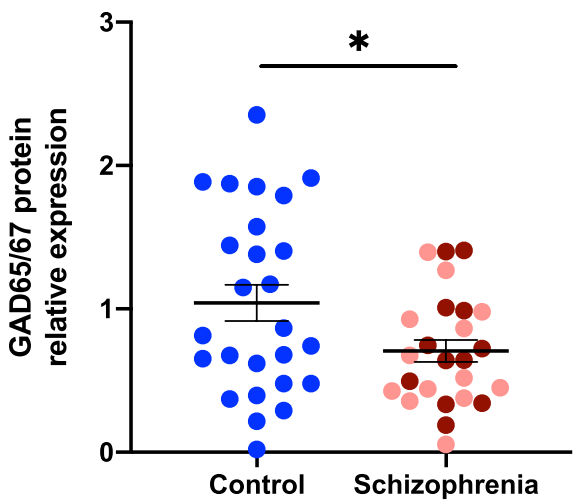

C.

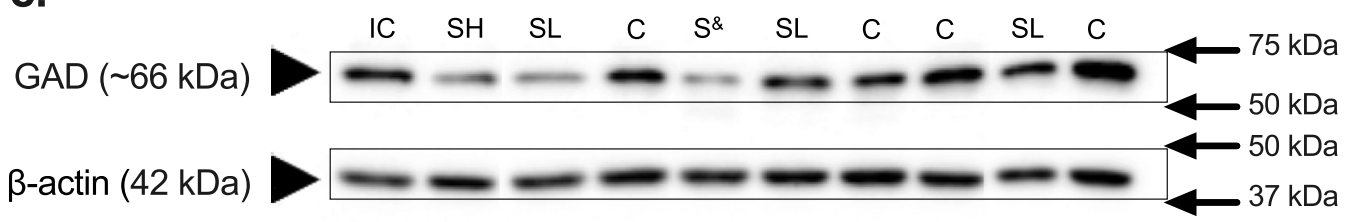

Fig. 1 Gene (GAD1) and protein (GAD65/67) expression levels of glutamate decarboxylase (GAD) in the midbrain in schizophrenia. a GAD1 mRNA was $30.96 \%$ lower in schizophrenia cases relative to controls, and this was not exacerbated by inflammatory status. b GAD65/67 protein was $34.14 \%$ lower in schizophrenia cases compared to controls, and this was also independent of inflammatory status. Pink dots are low inflammatory/ schizophrenia cases, dark red dots are high inflammatory/schizophrenia cases. c A GAD65/67 protein band ( 66 kDa) was detected in all control and schizophrenia cases. $\beta$-actin ( $42 \mathrm{kDa}$ ) was used as a loading control. IC internal control, C control, SH schizophrenia high inflammatory, SL schizophrenia low inflammatory. \& inflammatory status unknown. Statistical results for analysis by inflammatory subgroup are in Table 3. Bars indicate mean \pm SEM. ${ }^{*} p<0.05,{ }^{* * *} p<0.0001$

Table 3 Statistical results for mRNA and protein levels when analysed by inflammatory subgroup

\begin{tabular}{|c|c|c|c|c|}
\hline Marker & Overall ANOVA & CTRL low vs SCZ low & CTRL low vs SCZ high & SCZ low vs SCZ high \\
\hline GAD1 mRNA & $F(2,49)=7.551 ; p=0.001^{* *}$ & $30.10 \% ; p<0.001^{* * *}$ & $31.88 \% ; p<0.001 * *$ & $p=0.655$ \\
\hline GAD65/67 protein & $F(2,46)=2.895, p=0.065$ & & & \\
\hline PV mRNA & $F(2,51)=2.751, p=0.073$ & & & \\
\hline SST mRNA & $F(2,49)=1.859, p=0.167$ & & & \\
\hline VGAT mRNA & $\mathrm{F}(2,52)=8.281, p=0.001 * *$ & $28.66 \% ; p=0.018^{*}$ & $43.94 \% ; p<0.001^{* * *}$ & $p=0.177$ \\
\hline GABRA1 mRNA & $\mathrm{F}(2,51)=9.221, p<0.0001^{* * * *}$ & $34.91 \%, p=0.004^{* *}$ & $44.85 \%, p<0.0001^{* * * *}$ & $p=0.368$ \\
\hline GABRA2 mRNA & $F(2,50)=2.605, p=0.084$ & & & \\
\hline GABRA3 mRNA & $\mathrm{F}(2,50)=9.788 ; p=0.0001^{* * * *}$ & $p=0.181$ & $35.68 \%, p<0.0001^{* * * *}$ & $27.72 \%, p=0.007^{* *}$ \\
\hline GABRA3 protein & $F(2,40)=1.157, p=0.325$ & & & \\
\hline GABRA5 mRNA & $F(2,49)=1.555, p=0.221$ & & & \\
\hline
\end{tabular}

Percentage reduction and result of post-hoc tests are reported when result of overall ANOVA was significant. Significant results are bolded ${ }^{*} p<0.05,{ }^{* *} p<0.01,{ }^{* * *} p<0.001$, ${ }^{* * *} p<0.0001$

exploratory due to small and uneven group sizes, and assumptions of normality and homogeneity of variance were not met.

\section{Results}

GAD gene and protein expression in the midbrain were lower in schizophrenia, but not different according to inflammatory status

As hypothesised, expression of GAD was lower at both mRNA and protein levels in the midbrain in schizophrenia. When analysed by diagnosis, midbrain GAD1 gene 

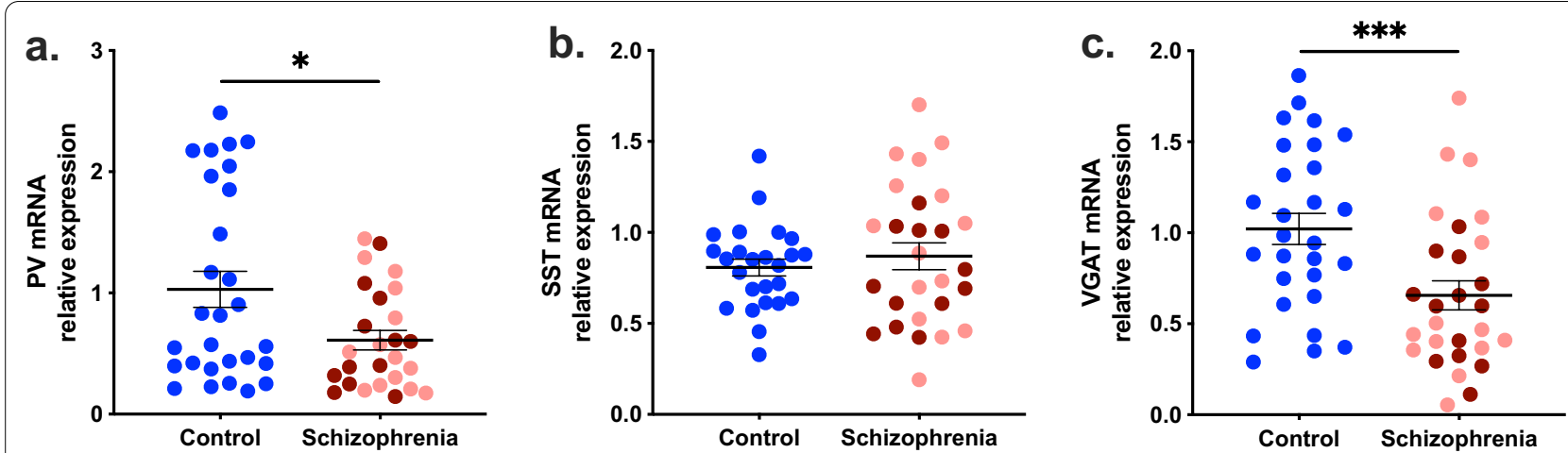

Fig. 2 Gene expression level of interneuron markers and vesicular GABA transporter in control and schizophrenia midbrain. a PV mRNA was lower in the midbrain of schizophrenia cases (by 40.70\%) relative to controls and this was not exacerbated by inflammatory status. b SST mRNA did not show significant changes in the midbrain between schizophrenia cases and controls. c VGAT mRNA was 39.69\% lower in schizophrenia cases compared with controls and this was also not exacerbated by inflammatory status. Pink dots are low inflammatory/schizophrenia cases, dark red dots are high inflammatory/schizophrenia cases. Statistical results for analysis by inflammatory subgroup are in Table 3. Bars indicate mean \pm SEM. ${ }^{*} p<0.05,{ }^{* * *} p<0.001$

expression was highly significantly decreased (30.96\%) when schizophrenia cases were compared to controls $(\mathrm{F}(1,50)=15.142 ; p<0.0001)$ (Fig. 1a). In contrast to our hypothesis, deficits in GAD1 mRNA were not exacerbated in the high inflammatory/schizophrenia subgroup (Table 3). Rather, GAD1 mRNA was expressed at lower and comparable levels in both inflammatory subgroups, $31.88 \%$ in the high inflammatory/schizophrenia subgroup and $30.10 \%$ in the low inflammatory/schizophrenia subgroup, compared to the control group $(\mathrm{F}(2,49)=7.551$; $p=0.001$, both schizophrenia-control comparisons $p<0.001$ ) (Table 3). GAD1 mRNA levels did not differ between the low and high inflammatory/schizophrenia subgroups $(p=0.655)$ (Table 3$)$.
Western blotting revealed an anti-GAD65/67 immunoreactive band at the expected size $(\sim 66 \mathrm{kDa})$ in all human midbrain cases (Fig. 1c) (a full Western Blot is shown in Additional file 1: Fig. S2A). Similar to GAD1 mRNA, when analysed by diagnosis, GAD65/67 protein expression was significantly decreased by $34.14 \%$ in the midbrain of schizophrenia cases compared to controls $(\mathrm{t}(41.286)=2.406, p=0.021$ ) (Fig. 1b). Although GAD65/67 protein expression was $30.05 \%$ and $36.73 \%$ lower in the midbrain in the high inflammatory and low inflammatory/schizophrenia subgroups, respectively, compared to controls, this did not reach statistical significance overall when analysed by inflammatory subgroup $(\mathrm{F}(2,46)=2.895, p=0.065)$ (Table 3$)$.
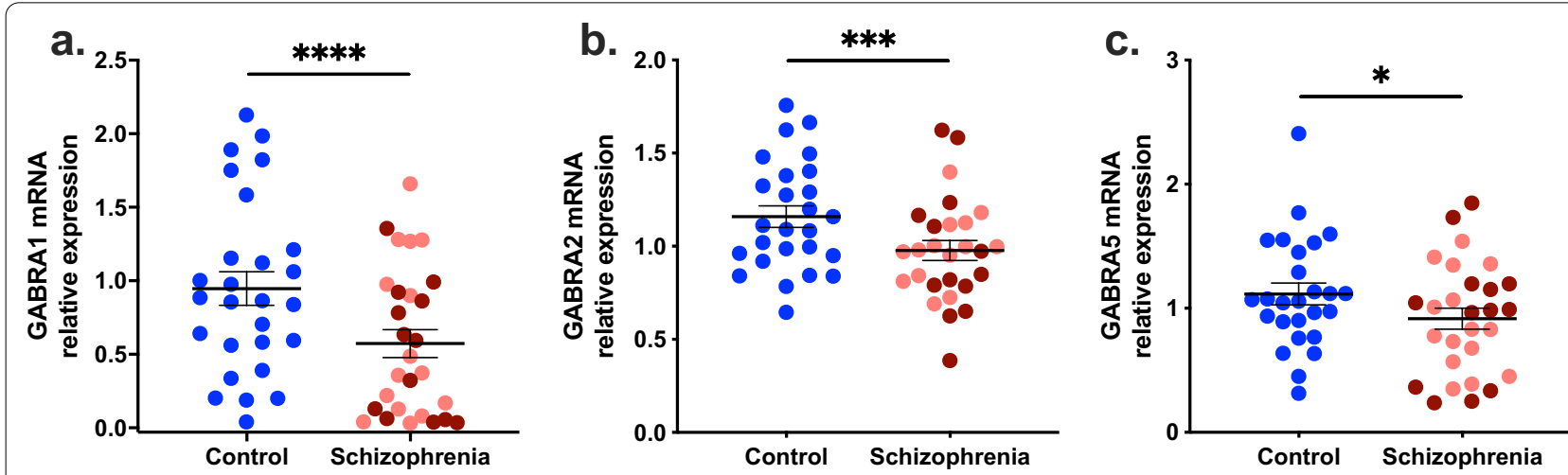

Fig. $3 \mathrm{GABA}_{A}$ receptor subunit gene expression in the midbrain in schizophrenia. a GABRA1 mRNA was $43.77 \%$ lower in the midbrain from schizophrenia cases compared with controls. b GABRA2 mRNA was $21.53 \%$ lower in the midbrain from schizophrenia cases compared with controls. c GABRA5 mRNA showed a decrease of $20.98 \%$ in the midbrain of schizophrenia cases compared with controls. Pink dots are low inflammatory/ schizophrenia cases, dark red dots are high inflammatory/schizophrenia cases. Reductions in GABRA1, 2 and 5 mRNA levels were not exacerbated by neuroinflammation. Statistical results for analysis by inflammatory subgroup are in Table 3. Bars indicate mean \pm SEM. ${ }^{*} p<0.05,{ }^{* * *} p<0.001$, ${ }^{* * * *} p<0.0001$ 

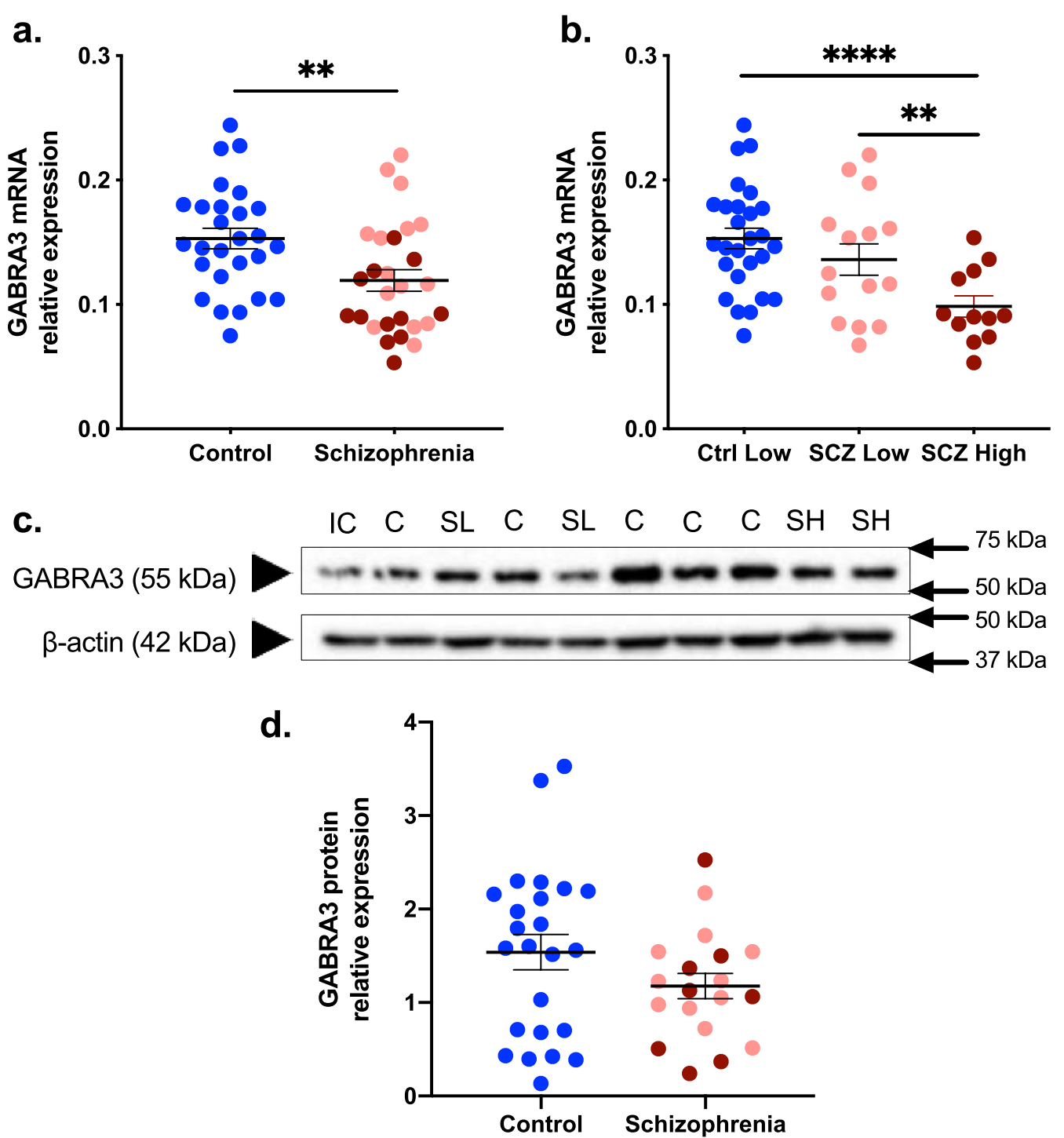

Fig. $4 G_{A B A}$ alpha 3 subunit gene expression in the midbrain of control and schizophrenia cases. a GABRA3 mRNA was 21.98\% lower in patients with schizophrenia relative to controls. b Reductions in GABRA3 mRNA were exacerbated in the high inflammatory/schizophrenia subgroup. GABRA3 mRNA was lower in high inflammatory/schizophrenia cases compared with both low inflammatory/schizophrenia cases and controls. There was no difference in GABRA3 mRNA between low inflammatory/schizophrenia cases compared with controls. $\mathrm{C} A \mathrm{GABA} A$ a3 subunit protein band was detected at $\sim 55 \mathrm{kDa}$ in human midbrain by an antibody raised against amino acids $6-125$. $\beta$-actin (42 kDa) was used as a loading control. d GABRA3 protein was $23.24 \%$ lower in schizophrenia cases relative to controls, though this change did not reach statistical significance. Pink dots are low inflammatory/schizophrenia cases, dark red dots are high inflammatory/schizophrenia cases. SCZ schizophrenia, IC internal control, C control, SH schizophrenia high inflammatory, SL schizophrenia low inflammatory. Statistical results for analysis by inflammatory subgroup are also in Table 3. Bars indicate mean \pm SEM. ${ }^{* *} p<0.01 .,{ }^{* * * *} p<0.0001$

PV and VGAT mRNAs were decreased in the midbrain in schizophrenia, whereas SST mRNA was unchanged As predicted, $P V$ mRNA was decreased by $40.70 \%$ in the midbrain of schizophrenia cases relative to controls $(\mathrm{t}(52)=2.349, p=0.023)$ (Fig. 2a) and this decrease was independent of inflammatory status (Table 3). Contrary to our hypothesis, SST mRNA was unchanged in the midbrain of schizophrenia cases compared to controls $(\mathrm{t}(43.071)=-0.705, p=0.485)$ (Fig. 2b) or when analysed by inflammatory subgroup $(\mathrm{F}(2,49)=1.859, p=0.167)$ (Table 3).

VGAT mRNA was decreased (39.69\%) in the midbrain of schizophrenia cases relative to controls $(\mathrm{F}(1,52)=17.733 ; \quad p=0.0001) \quad($ Fig. 2c). Analysis by 
inflammatory subgroup $(\mathrm{F}(2,52)=8.281, p=0.001)$ indicated that this decrease was due to reductions in both the inflammatory/schizophrenia subgroups (28.66\%, low inflammatory, $p=0.018 ; 43.94 \%$, high inflammatory, $p<0.0001$ ), and no significant difference between the two schizophrenia inflammatory subgroups was identified $(p=0.177)$ (Table 3$)$.
Four GABA alpha subunit mRNAs were lower

in the midbrain in schizophrenia, with only GABRA3 mRNA reductions related to neuroinflammation

Gene expression of $\mathrm{GABA}_{\mathrm{A}}$ receptor alpha 1, 2, 3 and 5 subunits were significantly decreased in the midbrain of schizophrenia cases compared with controls. GABRA1 mRNA was $43.77 \%$ lower in the midbrain of schizophrenia cases compared with controls $(\mathrm{U}=156.0$; $p<0.0001$ ) (Fig. 3a). GABRA1 mRNA was significantly changed when analysed by inflammatory subgroup
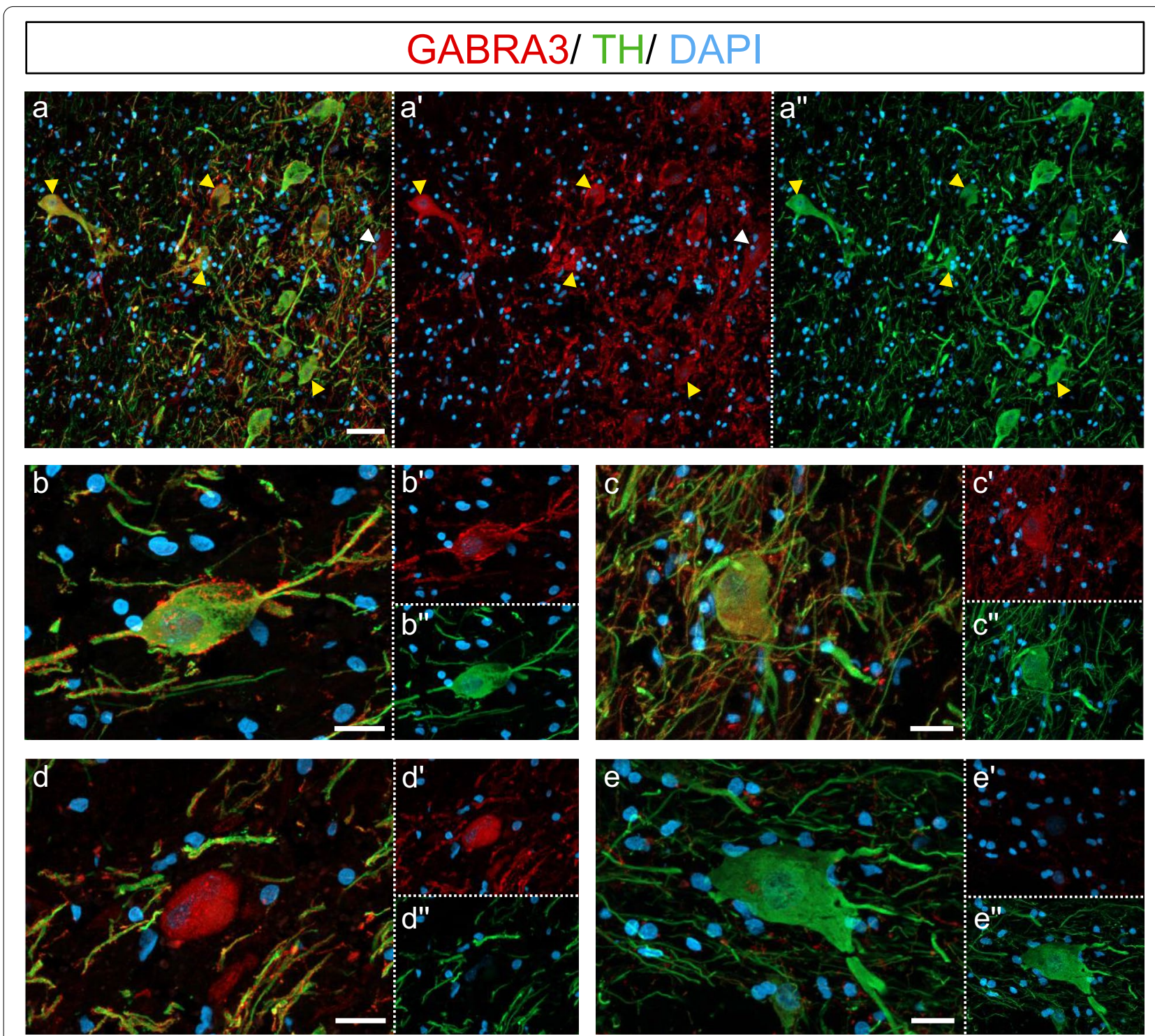

Fig. $5 G_{A B A}$ alpha 3 subunit expression was abundant in dopaminergic neurons in the midbrain. a Double-labelling immunohistochemistry revealed GABRA3 ${ }^{+} / \mathrm{TH}^{+}$neurons with variable levels of GABRA3 (yellow arrowheads) and GABRA3 ${ }^{+} / \mathrm{TH}^{-}$cells (white arrowhead) in the substantia nigra. GABRA3 expression was identified along the cell membrane and processes (b) and in the cytoplasm of $\mathrm{TH}^{+}$neurons $(\mathbf{c})$. GABRA3 ${ }^{+} / \mathrm{TH}^{-}$cells (d) and GABRA3 ${ }^{-} / \mathrm{TH}^{+}$neurons (e) were occasionally identified in the midbrain in schizophrenia and controls cases. Scale bars $=50 \mu \mathrm{m}$ (a) and $20 \mu \mathrm{m}(\mathbf{b}-\mathbf{e})$ 


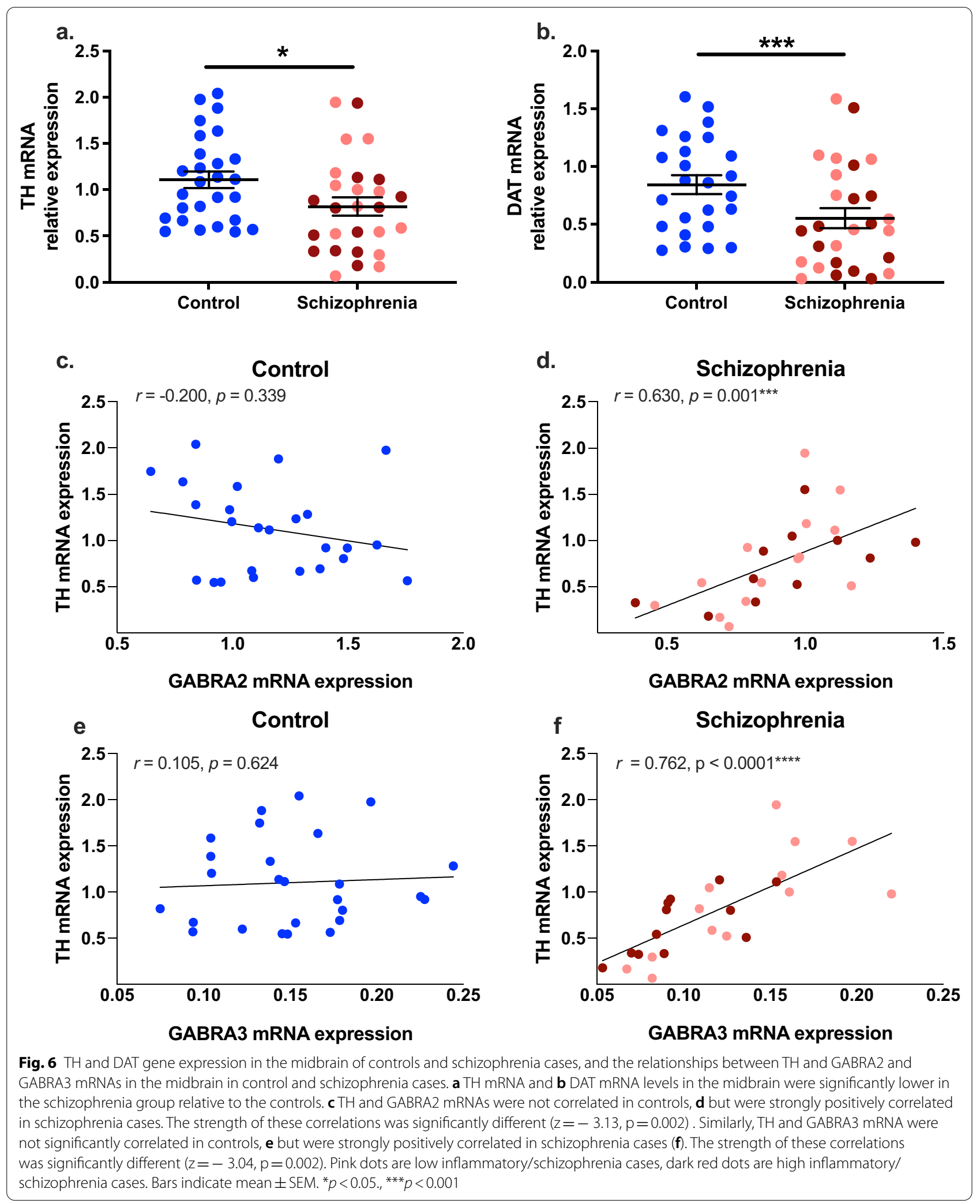


$(\mathrm{F}(2,51)=9.221, p<0.0001)$, however, whilst the control group was significantly different to both the low inflammatory $(34.91 \%, p=0.004)$ and high inflammatory $(44.85 \%, p<0.0001)$ schizophrenia subgroups, there was no significant difference between the low and high inflammatory/schizophrenia subgroups $(p=0.368)$ (Table 3).

GABRA2 mRNA was decreased by $21.53 \%$ in the midbrain in schizophrenia cases compared to controls $(\mathrm{t}(50)=3.369 ; \quad p=0.001) \quad$ (Fig. 3b) and was unchanged when analysed by inflammatory subgroup $(\mathrm{F}(2,50)=2.605, p=0.084)$ (Table 3$)$. There was a $20.98 \%$ decrease in GABRA5 mRNA $(\mathrm{F}(1,50)=4.913 ; p=0.031$; Fig. 3c) in the midbrain in schizophrenia cases relative to controls. GABRA5 mRNA levels were unchanged when comparing the high versus low inflammatory schizophrenia subgroups (Table 3 ).

By diagnosis, GABRA3 mRNA was significantly decreased by $21.98 \%$ in the midbrain in schizophrenia cases compared with controls $(\mathrm{F}(1,51)=10.128$, $p=0.002$ ) (Fig. 4a). When analysed by inflammatory subgroup, lower levels of GABRA3 mRNA in the midbrain were only found in the high inflammatory/ schizophrenia subgroup. Levels of GABRA3 mRNA $(\mathrm{F}(2,50)=9.788 ; p<0.0001)$ were significantly lower, by $35.68 \%$ in the high inflammatory/schizophrenia subgroup compared to controls $(p<0.0001)$ and by $27.72 \%$ in the high inflammatory/schizophrenia subgroup compared to the low inflammatory/schizophrenia subgroup $(p=0.007)$ (Fig. 4b) (Table 3). GABRA3 mRNA in the low inflammatory/schizophrenia subgroup was not significantly different to the control group $(p=0.181)$.

Western blotting revealed an expected prominent GABRA3 protein band of $\sim 55 \mathrm{kDA}$ (Fig. 4c) (a full
Western Blot is shown in Additional file 1: Fig. S2B). Diagnostically, GABRA3 protein levels were $23.24 \%$ lower in schizophrenia, however this change did not reach statistical significance $(\mathrm{t}(45)=1.519, \mathrm{p}=0.136)$ (Fig. 4d). GABRA3 protein levels were unchanged by inflammatory subgroup $(\mathrm{F}(2,40)=1.157, \mathrm{p}=0.325)$ (Table 3).

Double-labelling immunohistochemistry revealed GABRA3 expression often overlapped with TH expression irrespective of diagnostic groups (Fig. 5a). GABRA3 was often expressed along the cell membrane (Fig. 5b) and in the cytoplasm of $\mathrm{TH}^{+}$neurons (Fig. 5c). When counting double-labelled $\mathrm{GABRA}^{+} / \mathrm{TH}^{+}$and singlelabelled GABRA3 ${ }^{-} / \mathrm{TH}^{+}$neurons in 3 control and 3 high inflammatory/schizophrenia cases, we identified GABRA3 expression in $98 \%$ of $\mathrm{TH}^{+}$neurons, irrespective of diagnostic group. In addition to the abundant co-localisation of GABRA3 and TH, we identified some single-labelled GABRA3 ${ }^{+} / \mathrm{TH}^{-}$cells (Fig. $5 \mathrm{~d}$ ) and the occasional GABRA3 ${ }^{-} / \mathrm{TH}^{+}$cell in the SN (Fig. 5e).

\section{GABRA2 and GABRA3 mRNAs were strongly positively associated with $T H$ and DAT mRNAs in schizophrenia}

In contrast to previously reported, whereby lower $\mathrm{TH}$ mRNA levels in the schizophrenia cases did not reach statistical significance [17], TH mRNA was significantly lower in the schizophrenia group compared to the control group $t(52)=2.175, \mathrm{p}=0.012$ (Fig. 6a). Similar to previously reported [17], DAT mRNA was significantly lower in the schizophrenia group compared to controls $[\mathrm{F}(1,50)=10.306, \mathrm{p}=0.002$ (RIN)] (Fig. 6b).

GABRA2 $(r=0.630, p=0.001)$, and GABRA3 $(r=0.762$, $p<0.0001)$ mRNAs were significantly positively correlated with $T H$ mRNA in schizophrenia cases, but not in

Table 4 Correlations between GABAergic transcripts and TH and DAT mRNAs in control and schizophrenia cases. Differences between the correlation coefficients were assessed with Fisher's r-to-z transformation

\begin{tabular}{|c|c|c|c|c|c|c|c|c|}
\hline \multirow[t]{2}{*}{ Transcripts } & \multicolumn{3}{|c|}{ CONTROL } & \multicolumn{3}{|c|}{ SCHIZOPHRENIA } & \multicolumn{2}{|c|}{$\begin{array}{l}\text { Fisher's r-to-z } \\
\text { transformation }\end{array}$} \\
\hline & $r$ & $\mathrm{p}$ & $\mathrm{n}$ & $r$ & $p$ & $\mathrm{n}$ & $z$ & $p$ \\
\hline \multicolumn{9}{|l|}{$\mathrm{TH}$} \\
\hline GABRA1 & 0.159 & 0.447 & 26 & 0.456 & $0.022^{*}$ & 26 & -1.13 & 0.259 \\
\hline GABRA2 & -0.200 & 0.339 & 25 & 0.630 & $0.001 * * *$ & 25 & -3.13 & $0.002^{* *}$ \\
\hline GABRA3 & 0.105 & 0.624 & 26 & 0.762 & $<0.0001^{* * * *}$ & 26 & -3.04 & $0.002^{* *}$ \\
\hline GABRA5 & 0.304 & 0.140 & 25 & 0.250 & 0.228 & 26 & 0.20 & 0.842 \\
\hline \multicolumn{9}{|l|}{ DAT } \\
\hline GABRA1 & 0.336 & 0.093 & 27 & 0.526 & $0.008^{* *}$ & 25 & -0.80 & 0.424 \\
\hline GABRA2 & -0.030 & 0.887 & 26 & 0.790 & $<0.0001^{* * * *}$ & 24 & -3.65 & $<0.001^{* * *}$ \\
\hline GABRA3 & 0.310 & 0.132 & 27 & 0.847 & $<0.0001^{* * * *}$ & 25 & -3.13 & $0.017^{*}$ \\
\hline GABRA5 & 0.472 & $0.017^{*}$ & 26 & 0.320 & 0.127 & 25 & 0.61 & 0.542 \\
\hline
\end{tabular}

Bold text indicates statistically significant data

${ }^{*} p<0.05,{ }^{* *} p<0.01,{ }^{* * *} p<0.005,{ }^{* * * *} p<0.0001$ 
control cases $(r=-0.200, p=0.339 ; r=0.105, p=0.624$, respectively), and these correlations were significantly different when comparing diagnostic groups (GABRA2: $\mathrm{z}=-3.13, p=0.002$ and GABRA3: $\mathrm{z}=-3.04, p=0.002)$ (Fig. 6c-f, Table 4).

Similar relationships were evident between these two subunits and DAT mRNA (Table 4). GABRA2 $(r=0.790$, $p<0.0001)$, and GABRA3 ( $r=0.847, p<0.0001)$ mRNAs were significantly positively correlated with $D A T$ mRNA in schizophrenia cases, but not in control cases ( $r=-0.030, p=0.887 ; r=0.310, p=0.132$, respectively), and these correlations were significantly different when comparing diagnostic groups (GABRA2: $\mathrm{z}=-3.65$, $p<0.001$ and GABRA3: $\mathrm{z}=-3.13, p=0.017$ ) (Table 4).

GABRA1 mRNA was not significantly correlated with $T H$ and DAT mRNAs in controls (both: $r<0.336, p>0.05$ ) but was positively correlated with $\mathrm{TH}$ and DAT mRNAs in schizophrenia cases (both: $r>0.456, p<0.05$ ) (Table 4). GABRA5 mRNA was significantly positively correlated with $D A T$ mRNA $(r=0.472, p=0.017)$ but not $T H$ mRNA $(r=0.304, p=0.140)$ in controls cases and was not correlated with $T H$ or DAT mRNAs in schizophrenia cases (both: $r<0.320, p>0.05$ ) (Table 4). However, neither GABRA1 or GABRA5 mRNAs exhibited significantly changed relationships with $T H$ or $D A T$ mRNAs between control and schizophrenia (all: $\mathrm{z}<1.13, p>0.05$ ) (Table 4).

\section{Relationship of genes of interest to clinical and ante-mortem variables}

No measures of antipsychotic treatment (last, mean daily, and lifetime chlorpromazine equivalent dose) were significantly correlated with expression of any gene of interest (Additional file 1: Table S3). GAD1 mRNA levels were significantly higher in schizophrenia patients that died by suicide compared to schizophrenia cases that died by non-suicide causes $(\mathrm{t}(25)=-2.071, p=0.049)$ (Additional file 1: Table S4). GAD protein levels were significantly positively correlated with duration of illness $(r=0.490$, $p=0.015$ ) (Additional file 1: Table S3). No genes of interest differed by agonal state, smoking, antipsychotic type, symptom category (positive vs negative) or severity (treatment resistance), or lifetime depression status (Additional file 1: Table S4, all $p>0.05$ ).

\section{Discussion}

We found pronounced deficits in transcripts and proteins involved in GABA synthesis, vesicular packaging and signal transduction in the ventral midbrain in schizophrenia compared to controls. Contrary to our prediction, these reductions in GABAergic markers, including $G A D$ mRNA and protein, VGAT, PV, GABRA1, GABRA2, and GABRA5 mRNAs, with the exception of GABRA3 mRNA, were not exacerbated by neuroinflammation.
Interestingly, the unexpected positive relationship detected between DA transcripts and some GABA receptor transcripts was contrary to the predicted negative relationship [22], and indicates an aberrant relationship between these two neurotransmitter systems at the level of the midbrain in schizophrenia. These molecular changes related to midbrain inhibitory neurotransmission appear to be intrinsic to the disease state, as they are generally not exacerbated by a higher inflammatory state nor indeed directly correlated with antipsychotic usage. This study is the first to provide evidence for blunted GABAergic neurotransmission in the post-mortem ventral midbrain in schizophrenia.

The reduction in gene expression of the GABA synthesis enzyme, GAD1, suggests that there is less production of GABA within neuron cell bodies in the midbrain in schizophrenia. This is also reflected in lower GAD protein expression, although protein measurements incorporate GAD synthesised within the midbrain, as well as GAD expressed by terminals projecting to the midbrain and synthesised elsewhere [76]. Our report of lower $V G A T$ mRNA expression supports that there may be less inhibition in the midbrain in schizophrenia, and aligns with a study indicating that less GAD activity decreases VGAT activity [77]. In conjunction with lower VGAT mRNA, suggesting that less packaging of GABA into the synaptic vesicles of these neurons may occur, our results suggest that there may be less GABA released into the synaptic cleft to bind to diminished postsynaptic GABA receptors and thus less inhibitory action within the midbrain. This is supported by an electron microscopy study that reported a decrease in inhibitory synapses in the midbrain in schizophrenia (8 controls, 11 schizophrenia cases) [78]. Our findings in the midbrain concord with the widespread reduction of GAD mRNA and protein across multiple brain regions in schizophrenia [25-29], although they are in contrast to a single immunoblotting study in the midbrain demonstrating increased GAD67 protein in schizophrenia (12 control, 13 schizophrenia cases) [30]. In this study the authors reported that the increase in GAD67 protein occurred only in patients on antipsychotics at the time of death $(n=9)$ and suggested that this may reflect a compensatory mechanism in response to chronic antipsychotic medication. However, all cases in our cohort $(n=28)$ were on antipsychotics at the time of death, yet we report lower GAD at both mRNA and protein levels, suggesting that any possible increase in GAD67 by antipsychotic treatment is insufficient to restore GAD67 levels to control levels in our cohort. However, we also found that despite the overall decrease, GAD protein levels were positively correlated with duration of illness in schizophrenia patients, such that those who have been ill for longer 
have proportionally higher levels of GAD. Together with Schoonover et al. [30], this suggests that longer exposure to antipsychotics may recover a deficit in GAD levels in schizophrenia. However, we did not detect any significant relationships between lifetime, mean daily or last dose measures of antipsychotic exposure and GAD protein or mRNA levels in our cohort. In support of this, GAD1 mRNA is unchanged in the cortex of monkeys treated chronically with antipsychotics $[29,79]$, and three schizophrenia cases with lower levels of cortical GAD1 mRNA, who were not on antipsychotics, also showed lower GABA-related transcripts[79]. However, rodent studies indicate that antipsychotics sometimes have no impact, occasionally decrease and most often increase GABA indices [80-85]. In conclusion, while it is possible that antipsychotics could increase measures of inhibitory neurotransmission, they are not likely responsible for the decrease in GAD mRNA or protein levels that we report.

An important consideration when comparing the limited studies in the post-mortem midbrain is the anatomical level of the tissue. Schoonover et al. (2017) [30] utilised tissue from the caudal midbrain, Mabry et al. (2019) [78] used tissue from the middle of the rostrocaudal extent and our tissue was dissected from a rostral portion of the midbrain at the exit of the occulomotor nerve [17]; thus, it is possible that distinct changes in inhibitory action occur at different levels of the midbrain in people with schizophrenia. Taken together with the report of a reduction in inhibitory synapses in the midbrain in schizophrenia [78], we suggest that fewer inhibitory terminals may exist in the midbrain in conjunction with decreases in a key enzyme involved in GABA synthesis and vesicular GABA transporter, supporting the notion of less inhibitory control in the region of dopamine cell bodies in schizophrenia. Interestingly, in primates, rostral to caudal topographical organisation of basal ganglia circuitry controls different behaviours in parallel circuits [86]. Dopamine neurons in the rostral-ventral-medial SN project to the caudate head while those in the caudaldorsal-lateral SN project to the caudate tail [87]. Caudate head-projecting DA neurons guide controlled behaviour, whereas caudate tail-projecting DA neurons guide automatic behaviour [86, 87]. Since GABAergic SNpr neurons send axon collaterals to adjacent DAergic SNpc neurons [21], this rostral-caudal organisation may also extend to inhibitory neuron control, suggesting that different changes in inhibitory control along this axis may impact distinct behaviours. We speculate that the potential loss of inhibitory control at a relatively rostral midbrain level would be most likely to impact more complex behaviour and striatal learning, both known to be altered at the behavioural and functional level in schizophrenia (e.g. $[88,89])$.
In terms of which specific subcellular populations of GABAergic neurons are impacted, we found that $P V$ mRNA was significantly lower in schizophrenia cases, at a magnitude of $\sim 40 \%$, akin to some reports in the cortex which range from $13 \%$ to $>50 \%[38,39]$. In contrast, and contrary to our hypothesis, SST mRNA was unchanged in our midbrain cohort, suggesting that there may be subtype specificity to the putative inhibitory neuron deficit and that this midbrain pathology is a notable distinction from the cortex where both $\mathrm{PV}+$ and SST + populations are impacted $[7,28,32,36-39]$. Since PV + GABAproducing neurons with cell bodies located in the $\mathrm{SNpr}$, project to the $\mathrm{SNpc}$ as well as other regions in the basal ganglia, the reduction in $P V$ mRNA implicates the projection neurons of the SNpr in the potential GABAergic dysregulation in schizophrenia [40, 90]. Although it is a limitation of our study that we do not distinguish whether changes occur in a particular subpopulation of $\mathrm{PV}+$ neurons, our data suggests that GABAergic deficits in the midbrain may have implications for less overall inhibitory control throughout the basal ganglia in addition to a more local impact on the dopaminergic cell bodies forming the nigrostriatal pathway.

Our study showed that potential GABAergic dysregulation in the midbrain also extends to alterations in transcripts encoding postsynaptic GABAergic receptors. We showed the most substantial reduction (43.77\%) in GABRA1 mRNA, which encodes for the $\mathrm{GABA}_{\mathrm{A}} \alpha 1$ subunit that constitutes the $\alpha 1 \beta 2 \gamma 2$ receptor subtype, the most highly expressed $\mathrm{GABA}_{\mathrm{A}}$ subtype in the brain $[62,91]$. Although multiple subunits are identified in the midbrain [69], the subunit composition of $\mathrm{GABA}_{\mathrm{A}}$ receptor subtypes specifically in the midbrain is not well established. However, the vast majority of $\alpha 1$ is detected on GAD67 + neurons within the SNpr, with low (7\%) or no expression on pigmented $(\mathrm{TH}+)$ neurons of the $\mathrm{SNpc}$ $[64,65,68,69,92]$. Thus, reduction in $\mathrm{GABA}_{\mathrm{A}} \alpha 1$ may be occurring on both GABA and dopamine neurons in the midbrain in schizophrenia. However, the direct implications of lower levels of $\mathrm{GABA}_{\mathrm{A}}$ receptor mRNAs for dopaminergic neurotransmission in the $\mathrm{SN}$ remain unclear. We found relationships between molecular markers of GABAergic and dopamine neurotransmission in the midbrain. Despite the substantial reduction in GABRA1 mRNA in schizophrenia, positive correlations between GABRA1 mRNA and dopaminergic (TH and $D A T$ ) mRNAs did not differ diagnostically, suggesting that, although there may be less $\alpha 1$ available in the midbrain in schizophrenia, the normal link between the $\alpha 1$ subunit and dopamine synthesis and transport remains intact. A limitation of our study is that we have not measured $\mathrm{GABA}_{\mathrm{A}}$ beta or gamma subunits, which are highly expressed in (rat) midbrain [65, 69]. However, 
convergence of a reduction and dysregulation of multiple $\mathrm{GABA}_{\mathrm{A}} \alpha$ subunits is likely to contribute to schizophrenia pathophysiology in the midbrain.

We did measure gene expression of three other $\mathrm{GABA}_{\mathrm{A}}$ receptor subunits and found consistent downregulation of $\alpha 2, \alpha 3$, and $\alpha 5$ in the midbrain in schizophrenia. The $\mathrm{GABA}_{\mathrm{A}} \alpha 3$ subunit is expressed on the dopaminergic neurons of the SNpc [63, 66], and we showed, similar to rat midbrain [69], 98\% of dopaminergic neurons in the human midbrain have GABRA3 immunoreactivity in both controls and schizophrenia cases. The pattern of immunopositive $\alpha 3$ staining indicates the $\alpha 3$ subunit likely contributes to the composition of cell surface $\mathrm{GABA}_{\mathrm{A}}$ receptors on dopamine neurons. To our knowledge, the $\alpha 3$ subunit has not been studied before in schizophrenia, though an animal model suggests a direct link between the absence of this receptor and a hyperdopaminergic phenotype [93], supporting the notion that an overall reduction in $\mathrm{GABA}_{\mathrm{A}}$ receptors containing this subunit in the SN may enable disinhibition of dopaminergic neurons and contribute to nigrostiatal dopamine dysregulation. A caveat is that we did not detect significantly lower GABRA3 protein in the midbrain homogenates. However, this may be due to Western blotting being a less sensitive method with greater inherent variance. In addition, we found that GABRA3 and GABRA2 mRNAs were highly positively correlated with $T H$ and $D A T$ mRNAs in schizophrenia cases but not controls. As such, despite overall reductions in transcripts, positive correlations suggest that levels of these $\mathrm{DA}$ and $\mathrm{GABA}_{\mathrm{A}}$ receptor transcripts are changed in concert in schizophrenia. We can speculate that higher $\mathrm{TH}$ levels would lead to more $\mathrm{DA}$ synthesis and correspondingly higher $\mathrm{GABA}_{\mathrm{A}}$ receptor levels may therefore reflect a compensatory response to attenuate DA neurotransmission. Conversely, higher DAT levels in concert with increased inhibition would potentially yield an opposing effect on DA neurotransmission, as more DAT would mean a greater propensity to terminate dopamine neurotransmission. Thus, in schizophrenia midbrain, altered local interactions, which are established as crucially important to the functioning of the SN, between SNpr GABAergic neurons and DAergic neurons [21] may result in a functional change in the local inhibitory control of dopamine neurotransmission in the disease state.

The decrease in GABRA3 mRNA was the only change that was consistent with our hypothesis that GABA deficits would be most pronounced in cases with a high inflammatory biotype. We previously established that the midbrain is a site of convergence of macrophage presence, microglial activation, and enhanced activity of the complement cascade [54,55], and the convergence of these inflammatory processes may lead to disruption of neurotransmitter systems within the midbrain. It is possible that a global deficit in GABAergic neurotransmission and a heightened state of neuroinflammation in the midbrain coalesce to impact the GABRA3-expressing dopaminergic neurons of the nigrostriatal pathway, although mechanistic studies are needed to test this hypothesis.

We also detected significant reductions in GABRA2 and GABRA5 transcripts, although previous studies of their cellular location are contradictory. In the mouse brain, GABRA5 mRNA is not detected but GABRA2 mRNA is found in $99.5 \%$ of $\mathrm{TH}+$ cells in the SNpc [69], yet only weak immunohistochemical labelling of the $\alpha 2$ subunit is identified in the rat SNpc [65]. Previous studies in human midbrain failed to identify either mRNA, using in situ hybridisation, or protein measurements for the $\alpha 2$ subunit [66]. However, we detected GABRA2 mRNA in the human midbrain (albeit at lower levels than GABRA1 mRNA) with RT-qPCR which is inherently more sensitive to amplifying low abundant transcripts than in situ hybridisation. We previously used the same primer and probe set to amplify GABRA2 transcripts in the human cortex [25], and in agreement with previous studies [69], we have also detected GABRA2 transcripts in the rat substantia nigra (Additional file 1: Fig. S3). In addition, we showed a diagnostic difference in the relationships between GABRA2 (but not GABRA5) mRNA and TH and DAT mRNAs, suggesting that our GABRA2 mRNA measures are bona fide. We suggest that the tandem disruptions in the relationships between dopamine transcripts and GABA receptor $\alpha$ subunits may reveal the subunit composition of receptor subtypes that are most dysregulated in the midbrain in schizophrenia. Further studies are required to characterise cell-specific $\mathrm{GABA}_{\mathrm{A}}$ receptor subtypes in the human midbrain and how these may be altered in the dopamine neurons in schizophrenia.

The reduction in $\mathrm{GABA}_{\mathrm{A}}$ receptors in the brain in schizophrenia has formed the basis of $\mathrm{GABA}_{\mathrm{A}}$ receptor agonist (benzodiazepines) clinical trials; however, they have produced inconsistent results in schizophrenia patients. Our study supports animal studies that indicate that harnessing the ability to target GABA receptor subtypes based on their cellular specificity could bring about symptomatic attenuation in a more targeted manner [93-95], and thus may yet hold therapeutic potential. Our findings extend the body of evidence implicating GABAergic dysfunction in the pathophysiology of schizophrenia, to the main dopaminergic locus of the brain. We localised GABAergic dysregulation to neuronal populations that have cell bodies within the $\mathrm{SN}$, which may have implications for both the circuitry of the basal ganglia and for nigrostriatal dopaminergic neurotransmission in schizophrenia. Furthering our 
understanding of the underlying neurobiology within the midbrain in schizophrenia provides impetus for exploring GABA-related treatments specifically targeting this brain region.

\section{Supplementary Information}

The online version contains supplementary material available at https://doi. org/10.1186/s13041-021-00805-7.

Additional file 1. Supplementary methods, figures and tables

\section{Acknowledgements}

Not applicable

\section{Authors' contributions}

TPT and CSW contributed to study design and conception. All authors contributed to interpretation of results and edited the manuscript. AB performed qPCR and immunoblotting. DR and CW performed fluorescence immunohistochemistry and CW performed microscopy. AB, DR, and TPT contributed to statistical analysis. TPT and AB wrote the manuscript and TPT, AB and CSW interpreted the findings. All authors read and approved the final manuscript.

\section{Funding}

CSW is funded by the NSW Ministry of Health, Office of Health and Medical Research. CSW is a recipient of a National Health and Medical Research Council (Australia) Principal Research Fellowship (PRF) (\#1117079).

\section{Availability of data and materials}

The datasets analysed during the current study are available from the corresponding author on reasonable request.

\section{Declarations}

\section{Ethics approval and consent to participate}

Midbrain tissue was sourced from the NSW Brain Tissue Resource Centre and experiments were approved by the University of New South Wales Human Research Ethics Committee (HREC \#17826).

\section{Consent for publication}

Not applicable.

\section{Competing interests}

CSW is on an advisory board for Lundbeck, Australia Pty Ltd and in collaboration with Astellas Pharma Inc., Japan. The other authors all declare that they have no competing interests.

\section{Author details}

${ }^{1}$ Schizophrenia Research Laboratory, Neuroscience Research Australia, 139 Barker Street, Margarete Ainsworth Building, Level 5, Randwick, NSW 2031, Australia. ${ }^{2}$ School of Psychiatry, Faculty of Medicine, University of New South Wales, Sydney, NSW 2052, Australia. ${ }^{3}$ Department of Neuroscience \& Physiology, Upstate Medical University, Syracuse, NY 13210, USA.

Received: 10 February 2021 Accepted: 7 June 2021

Published online: 26 June 2021

\section{References}

1. Meyer-Lindenberg A, Miletich RS, Kohn PD, Esposito G, Carson RE, Quarantelli M, Weinberger DR, Berman KF. Reduced prefrontal activity predicts exaggerated striatal dopaminergic function in schizophrenia. Nat Neurosci. 2002;5(3):267-71.

2. Howes OD, Kapur S. The dopamine hypothesis of schizophrenia: version III-the final common pathway. Schizophr Bull. 2009;35(3):549-62.
3. Tepper JM, Martin LP, Anderson DR. GABAA receptor-mediated inhibition of rat substantia nigra dopaminergic neurons by pars reticulata projection neurons. J Neurosci. 1995;15(4):3092-103.

4. Waszczak BL, Bergstrom DA, Walters JR. Single unit responses of substantia nigra and globus pallidus neurons to GABA agonist and antagonist drugs. Adv Biochem Psychopharmacol. 1981;30:79-94.

5. Bolam JP, Smith Y. The GABA and substance $P$ input to dopaminergic neurones in the substantia nigra of the rat. Brain Res. 1990;529(1-2):57-78.

6. Morello F, Partanen J. Diversity and development of local inhibitory and excitatory neurons associated with dopaminergic nuclei. FEBS Lett. 2015;589(24):3693-701.

7. Hashimoto T, Bazmi HH, Mirnics K, Wu Q, Sampson AR, Lewis DA. Conserved regional patterns of GABA-related transcript expression in the neocortex of subjects with schizophrenia. Am J Psychiatry. 2008;165(4):479-89.

8. Konradi C, Yang CK, Zimmerman El, Lohmann KM, Gresch P, Pantazopoulos H, Berretta S, Heckers S. Hippocampal interneurons are abnormal in schizophrenia. Schizophr Res. 2011;131(1-3):165-73.

9. Fatemi SH, Folsom TD, Rooney RJ, Thuras PD. Expression of GABAA a2-, $\beta 1$ - and $\varepsilon$-receptors are altered significantly in the lateral cerebellum of subjects with schizophrenia, major depression and bipolar disorder. Transl Psychiatry. 2013;3(9):e303-e303.

10. Fatemi SH, Stary JM, Earle JA, Araghi-Niknam M, Eagan E. GABAergic dysfunction in schizophrenia and mood disorders as reflected by decreased levels of glutamic acid decarboxylase 65 and $67 \mathrm{kDa}$ and Reelin proteins in cerebellum. Schizophr Res. 2005;72(2-3):109-22.

11. Thompson M, Weickert CS, Wyatt E, Webster MJ. Decreased glutamic acid decarboxylase(67) mRNA expression in multiple brain areas of patients with schizophrenia and mood disorders. J Psychiatr Res. 2009;43(11):970-7.

12. Egerton A, Chaddock CA, Winton-Brown TT, Bloomfield MAP, Bhattacharyya S, Allen P, McGuire PK, Howes OD. Presynaptic striatal dopamine dysfunction in people at ultra-high risk for psychosis: findings in a second cohort. Biol Psychiat. 2013;74(2):106-12.

13. Laruelle M. The second revision of the dopamine theory of schizophrenia: implications for treatment and drug development. Biol Psychiat. 2013;74(2):80-1.

14. Kegeles LS, Abi-Dargham A, Frankle W, et al. Increased synaptic dopamine function in associative regions of the striatum in schizophrenia. Arch Gen Psychiatry. 2010;67(3):231-9.

15. Howes OD, Williams M, Ibrahim K, Leung G, Egerton A, McGuire PK, Turkheimer F. Midbrain dopamine function in schizophrenia and depression: a post-mortem and positron emission tomographic imaging study. Brain. 2013;136(Pt 11):3242-51.

16. Watanabe Y, Tanaka H, Tsukabe A, Kunitomi Y, Nishizawa M, Hashimoto R, Yamamori H, Fujimoto M, Fukunaga M, Tomiyama N. Neuromelanin magnetic resonance imaging reveals increased dopaminergic neuron activity in the substantia nigra of patients with schizophrenia. PLOS ONE. 2014;9(8):e104619.

17. Purves-Tyson TD, Owens SJ, Rothmond DA, Halliday GM, Double KL, Stevens J, McCrossin T, ShannonWeickert C. Putative presynaptic dopamine dysregulation in schizophrenia is supported by molecular evidence from post-mortem human midbrain. Transl Psychiatry. 2017;7(1):e1003.

18. Abi-Dargham A, Rodenhiser J, Printz D, Zea-Ponce Y, Gil R, Kegeles LS, Weiss R, Cooper TB, Mann JJ, Van Heertum RL, Gorman JM, Laruelle M. Increased baseline occupancy of D2 receptors by dopamine in schizophrenia. Proc Natl Acad Sci USA. 2000;97(14):8104-9.

19. Misgeld U. Innervation of the substantia nigra. Cell Tissue Res. 2004;318(1):107-14.

20. Paladini CA, Tepper JM. Chapter 17-Neurophysiology of substantia nigra dopamine neurons: modulation by GABA and glutamate. In: Steiner $\mathrm{H}$, Tseng KY, editors. Handbook of behavioral neuroscience. New York: Elsevier; 2016. p. 335-60.

21. Tepper JM, Lee CR. GABAergic control of substantia nigra dopaminergic neurons. Prog Brain Res. 2007;160:189-208.

22. Garbutt JC, van Kammen DP. The interaction between GABA and dopamine: implications for schizophrenia. Schizophr Bull. 1983;9(3):336-53.

23. Soghomonian JJ, Martin DL. Two isoforms of glutamate decarboxylase: why? Trends Pharmacol Sci. 1998;19(12):500-5. 
24. Benes FM, Berretta S. GABAergic interneurons: implications for understanding schizophrenia and bipolar disorder. Neuropsychopharmacology. 2001;25(1):1-27.

25. Duncan CE, Webster MJ, Rothmond DA, Bahn S, Elashoff M, Shannon Weickert C. Prefrontal GABA(A) receptor alpha-subunit expression in normal postnatal human development and schizophrenia. J Psychiatr Res. 2010;44(10):673-81.

26. Akbarian S, Huang HS. Molecular and cellular mechanisms of altered GAD1/GAD67 expression in schizophrenia and related disorders. Brain Res Rev. 2006;52(2):293-304.

27. Rocco BR, Lewis DA, Fish KN. Markedly lower glutamic acid decarboxylase 67 protein levels in a subset of boutons in schizophrenia. Biol Psychiat. 2016;79(12):1006-15.

28. Volk DW, Edelson JR, Lewis DA. Altered expression of developmental regulators of parvalbumin and somatostatin neurons in the prefrontal cortex in schizophrenia. Schizophr Res. 2016;177(1-3):3-9.

29. Volk DW, Austin MC, Pierri JN, Sampson AR, Lewis DA. Decreased glutamic acid decarboxylase67 messenger RNA expression in a subset of prefrontal cortical gamma-aminobutyric acid neurons in subjects with schizophrenia. Arch Gen Psychiatry. 2000;57(3):237-45.

30. Schoonover KE, McCollum LA, Roberts RC. Protein markers of neurotransmitter synthesis and release in postmortem schizophrenia substantia nigra. Neuropsychopharmacology. 2017;42(2):540-50.

31. Fung SJ, Sivagnanasundaram S, Weickert CS. Lack of change in markers of presynaptic terminal abundance alongside subtle reductions in markers of presynaptic terminal plasticity in prefrontal cortex of schizophrenia patients. Biol Psychiatry. 2011;69(1):71-9.

32. Hoftman GD, Volk DW, Bazmi HH, Li S, Sampson AR, Lewis DA. Altered cortical expression of GABA-related genes in schizophrenia: illness progression vs developmental disturbance. Schizophr Bull. 2015;41(1):180-91.

33. Alfahel-Kakunda A, Silverman WF. Calcium-binding proteins in the substantia nigra and ventral tegmental area during development: correlation with dopaminergic compartmentalization. Brain Res Dev Brain Res. 1997;103(1):9-20.

34. McRitchie DA, Hardman CD, Halliday GM. Cytoarchitectural distribution of calcium binding proteins in midbrain dopaminergic regions of rats and humans. J Comp Neurol. 1996:364(1):121-50.

35. Markram H, Toledo-Rodriguez M, Wang Y, Gupta A, Silberberg G, Wu C. Interneurons of the neocortical inhibitory system. Nat Rev Neurosci. 2004;5(10):793-807.

36. Morris HM, Hashimoto T, Lewis DA. Alterations in somatostatin mRNA expression in the dorsolateral prefrontal cortex of subjects with schizophrenia or schizoaffective disorder. Cereb Cortex. 2008;18(7):1575-87.

37. Fung SJ, Fillman SG, Webster MJ, Shannon Weickert C. Schizophrenia and bipolar disorder show both common and distinct changes in cortical interneuron markers. Schizophr Res. 2014;155(1-3):26-30.

38. Fung SJ, Webster MJ, Sivagnanasundaram S, Duncan C, Elashoff M, Weickert CS. Expression of interneuron markers in the dorsolateral prefrontal cortex of the developing human and in schizophrenia. Am J Psychiatry. 2010;167(12):1479-88.

39. Hashimoto T, Volk DW, Eggan SM, Mirnics K, Pierri JN, Sun Z, Sampson AR, Lewis DA. Gene expression deficits in a subclass of GABA neurons in the prefrontal cortex of subjects with schizophrenia. J Neurosci. 2003;23(15):6315-26

40. Lee CR, Tepper JM. Morphological and physiological properties of parvalbumin- and calretinin-containing gamma-aminobutyric acidergic neurons in the substantia nigra. J Comp Neurol. 2007;500(5):958-72.

41. Deniau JM, Mailly P, Maurice N, Charpier S. The pars reticulata of the substantia nigra: a window to basal ganglia output. Prog Brain Res. 2007;160:151-72.

42. Grofova I, Deniau JM, Kitai ST. Morphology of the substantia nigra pars reticulata projection neurons intracellularly labeled with HRP. J Comp Neurol. 1982;208(4):352-68.

43. Mailly P, Charpier S, Menetrey A, Deniau JM. Three-dimensional organization of the recurrent axon collateral network of the substantia nigra pars reticulata neurons in the rat. J Neurosci. 2003;23(12):5247-57.

44. Nair-Roberts RG, Chatelain-Badie SD, Benson E, White-Cooper H, Bolam JP, Ungless MA. Stereological estimates of dopaminergic, GABAergic and glutamatergic neurons in the ventral tegmental area, substantia nigra and retrorubral field in the rat. Neuroscience. 2008;152(4-2):1024-31.
45. Mengod G, Rigo M, Savasta M, Probst A, Palacios JM. Regional distribution of neuropeptide somatostatin gene expression in the human brain. Synapse. 1992;12(1):62-74.

46. Cooper PE, Fernstrom MH, Rorstad OP, Leeman SE, Martin JB. The regional distribution of somatostatin, substance $P$ and neurotensin in human brain. Brain Res. 1981;218(1-2):219-32.

47. Sekar, A., A.R. Bialas, H. Rivera, A. Davis, T.R. Hammond, N. Kamitaki, K. Tooley, J. Presumey, M. Baum, V. Van Doren, G. Genovese, S.A. Rose, R.E. Handsaker, M.J. Daly, M.C. Carroll, B. Stevens, S.A. McCarroll, C. Schizophrenia Working Group of the Psychiatric Genomics. Schizophrenia risk from complex variation of complement component 4. Nature. 2016;530(7589):177-83.

48. Trepanier MO, Hopperton KE, Mizrahi R, Mechawar N, Bazinet RP. Postmortem evidence of cerebral inflammation in schizophrenia: a systematic review. Mol Psychiatry. 2016;21(8):1009-26.

49. Horváth S, Mirnics K. Immune system disturbances in schizophrenia. Biol Psychiatry. 2014;75(4):316-23.

50. Fillman SG, Cloonan N, Catts VS, Miller LC, Wong J, McCrossin T, Cairns M, Weickert CS. Increased inflammatory markers identified in the dorsolateral prefrontal cortex of individuals with schizophrenia. Mol Psychiatry. 2013;18(2):206-14.

51. Fillman SG, Sinclair D, Fung SJ, Webster MJ, Shannon Weickert C. Markers of inflammation and stress distinguish subsets of individuals with schizophrenia and bipolar disorder. Transl Psychiatry. 2014;4:e365.

52. Arion D, Unger T, Lewis DA, Levitt $P$, Mirnics K. Molecular evidence for increased expression of genes related to immune and chaperone function in the prefrontal cortex in schizophrenia. Biol Psychiatry. 2007;62(7):711-21.

53. Siegel BI, Sengupta EJ, Edelson JR, Lewis DA, Volk DW. Elevated viral restriction factor levels in cortical blood vessels in schizophrenia. Biol Psychiat. 2014;76(2):160-7.

54. Purves-Tyson TD, Weber-Stadlbauer U, Richetto J, Rothmond DA, Labouesse MA, Polesel M, Robinson K, Shannon Weickert C, Meyer U. Increased levels of midbrain immune-related transcripts in schizophrenia and in murine offspring after maternal immune activation. Mol Psychiatry. 2021;26(3):849-63.

55. Purves-Tyson TD, Robinson K, Brown AM, Boerrigter D, Cai HQ, Weissleder C, Owens SJ, Rothmond DA, ShannonWeickert C. Increased macrophages and C1qA, C3, C4 transcripts in the midbrain of people with schizophrenia. Front Immunol. 2020;11:2002.

56. Boerrigter D, Weickert TW, Lenroot R, O'Donnell M, Galletly C, Liu D, Burgess M, Cadiz R, Jacomb I, Catts VS, Fillman SG, Weickert CS. Using blood cytokine measures to define high inflammatory biotype of schizophrenia and schizoaffective disorder. J Neuroinflamm. 2017;14(1):188.

57. Zhang Y, Catts VS, Sheedy D, McCrossin T, Kril JJ, Shannon Weickert C. Cortical grey matter volume reduction in people with schizophrenia is associated with neuro-inflammation. Transl Psychiatry. 2016;6(12):e982-e982.

58. Beneyto M, Abbott A, Hashimoto T, Lewis DA. Lamina-specific alterations in cortical GABA(A) receptor subunit expression in schizophrenia. Cereb Cortex. 2011;21(5):999-1011.

59. Verdurand M, Fillman SG, Weickert CS, Zavitsanou K. Increases in [3H] muscimol and [3H]flumazenil binding in the dorsolateral prefrontal cortex in schizophrenia are linked to a4 and $\gamma 2 S$ mRNA levels respectively. PLOS ONE. 2013;8(1):e52724-e52724.

60. Mohler H. GABA(A) receptor diversity and pharmacology. Cell Tissue Res. 2006;326(2):505-16.

61. Sieghart W. Subunit composition and structure of GABAA-receptor subtypes. In: Enna SJ, Möhler H, editors. The GABA receptors. Totowa, NJ: Humana Press; 2007. p. 69-86.

62. Pirker S, Schwarzer C, Wieselthaler A, Sieghart W, Sperk G. GABA(A) receptors: immunocytochemical distribution of 13 subunits in the adult rat brain. Neuroscience. 2000;101(4):815-50.

63. Waldvogel HJ, Baer K, Faull RL. The localization of inhibitory neurotransmitter receptors on dopaminergic neurons of the human substantia nigra. J Neural Transm Suppl. 2009;73:59-70.

64. Waldvogel HJ, Baer K, Gai WP, Gilbert RT, Rees MI, Mohler H, Faull RL. Differential localization of GABAA receptor subunits within the substantia nigra of the human brain: an immunohistochemical study. J Comp Neurol. 2008;506(6):912-29. 
65. Fritschy JM, Mohler H. GABAA-receptor heterogeneity in the adult rat brain: differential regional and cellular distribution of seven major subunits. J Comp Neurol. 1995;359(1):154-94.

66. Petri S, Krampfl K, Dengler R, Bufler J, Weindl A, Arzberger T. Human GABA A receptors on dopaminergic neurons in the pars compacta of the substantia nigra. J Comp Neurol. 2002;452(4):360-6.

67. Schwarzer C, Berresheim U, Pirker S, Wieselthaler A, Fuchs K, Sieghart W, Sperk G. Distribution of the major gamma-aminobutyric acid(A) receptor subunits in the basal ganglia and associated limbic brain areas of the adult rat. J Comp Neurol. 2001;433(4):526-49.

68. Waldvogel HJ, Billinton A, White JH, Emson PC, Faull RL. Comparative cellular distribution of GABAA and GABAB receptors in the human basal ganglia: immunohistochemical colocalization of the alpha 1 subunit of the GABAA receptor, and the GABABR1 and GABABR2 receptor subunits. J Comp Neurol. 2004;470(4):339-56.

69. Okada H, Matsushita N, Kobayashi K, Kobayashi K. Identification of GABAA receptor subunit variants in midbrain dopaminergic neurons. J Neurochem. 2004;89(1):7-14.

70. Sonntag KC, Tejada G, Subburaju S, Berretta S, Benes FM, Woo TU. Limited predictability of postmortem human brain tissue quality by RNA integrity numbers. J Neurochem. 2016;138(1):53-9.

71. Mellios N, Huang HS, Baker SP, Galdzicka M, Ginns E, Akbarian S. Molecular determinants of dysregulated GABAergic gene expression in the prefrontal cortex of subjects with schizophrenia. Biol Psychiatry. 2009;65(12):1006-14

72. Weickert CS, Rothmond DA, Purves-Tyson TD. Considerations for optimal use of postmortem human brains for molecular psychiatry: lessons from schizophrenia. Handb Clin Neurol. 2018;150:221-35.

73. Joshi D, Fung SJ, Rothwell A, Weickert CS. Higher gamma-aminobutyric acid neuron density in the white matter of orbital frontal cortex in schizophrenia. Biol Psychiatry. 2012;72(9):725-33.

74. Schnell SA, Staines WA, Wessendorf MW. Reduction of lipofuscin-like autofluorescence in fluorescently labeled tissue. J Histochem Cytochem. 1999;47(6):719-30.

75. Hagihara H, Catts VS, Katayama Y, Shoji H, Takagi T, Huang FL, Nakao A, Mori Y, Huang KP, Ishii S, Graef IA, Nakayama KI, Shannon Weickert C, Miyakawa T. Decreased brain $\mathrm{pH}$ as a shared endophenotype of psychiatric disorders. Neuropsychopharmacology. 2018;43(3):459-68.

76. Mendez I, Elisevich K, Flumerfelt BA. GABAergic synaptic interactions in the substantia nigra. Brain Res. 1993;617(2):274-84.

77. Jin H, Wu H, Osterhaus G, Wei J, Davis K, Sha D, Floor E, Hsu C-C, Kopke RD, Wu J-Y. Demonstration of functional coupling between gamma -aminobutyric acid (GABA) synthesis and vesicular GABA transport into synaptic vesicles. Proc Natl Acad Sci USA. 2003;100(7):4293-8.

78. Mabry SJ, McCollum LA, Farmer CB, Bloom ES, Roberts RC. Evidence for altered excitatory and inhibitory tone in the post-mortem substantia nigra in schizophrenia. World J Biol Psychiatry. 2019;21(5):339-56.

79. Hashimoto T, Arion D, Unger T, Maldonado-Aviles JG, Morris HM, Volk DW, Mirnics K, Lewis DA. Alterations in GABA-related transcriptome in the dorsolateral prefrontal cortex of subjects with schizophrenia. Mol Psychiatry. 2008;13(2):147-61.

80. Yamamura S, Ohoyama K, Hamaguchi T, Kashimoto K, Nakagawa M, Kanehara S, Suzuki D, Matsumoto T, Motomura E, Shiroyama T, Okada M. Effects of quetiapine on monoamine, GABA, and glutamate release in rat prefrontal cortex. Psychopharmacology. 2009;206(2):243-58.

81. Yamamura S, Ohoyama K, Hamaguchi T, Nakagawa M, Suzuki D, Matsumoto T, Motomura E, Tanii H, Shiroyama T, Okada M. Effects of zotepine on extracellular levels of monoamine, GABA and glutamate in rat prefrontal cortex. Br J Pharmacol. 2009;157(4):656-65.
82. Weston-Green K, Huang XF, Deng C. Alterations to melanocortinergic, GABAergic and cannabinoid neurotransmission associated with olanzapine-induced weight gain. PLoS One. 2012;7(3):e33548.

83. Zink M, Schmitt A, May B, Muller B, Demirakca T, Braus DF, Henn FA. Differential effects of long-term treatment with clozapine or haloperidol on GABAA receptor binding and GAD67 expression. Schizophr Res. 2004;66(2-3):151-7.

84. Xu S, Gullapalli RP, Frost DO. Olanzapine antipsychotic treatment of adolescent rats causes long term changes in glutamate and GABA levels in the nucleus accumbens. Schizophr Res. 2015;161(2-3):452-7.

85. Osborne PG, O'Connor WT, Beck O, Ungerstedt U. Acute versus chronic haloperidol: relationship between tolerance to catalepsy and striatal and accumbens dopamine, GABA and acetylcholine release. Brain Res. 1994;634(1):20-30.

86. Kim HF, Hikosaka O. Parallel basal ganglia circuits for voluntary and automatic behaviour to reach rewards. Brain. 2015;138(Pt 7):1776-800.

87. Kim HF, Ghazizadeh A, Hikosaka O. Separate groups of dopamine neurons innervate caudate head and tail encoding flexible and stable value memories. Front Neuroanat. 2014;8:120.

88. Morris RW, Vercammen A, Lenroot R, Moore L, Langton JM, Short B, Kulkarni J, Curtis J, Donnell M, Weickert CS, Weickert TW. Disambiguating ventral striatum $\mathrm{AMRI}-$ related BOLD signal during reward prediction in schizophrenia. Mol Psychiatry. 2012;17(3):235.

89. Weickert TW, Goldberg TE, Callicott JH, Chen Q, Apud JA, Das S, Zoltick BJ, Egan MF, Meeter M, Myers C, Gluck MA, Weinberger DR, Mattay VS. Neural correlates of probabilistic category learning in patients with schizophrenia. J Neurosci. 2009;29(4):1244-54.

90. Beckstead RM, Frankfurter A. The distribution and some morphological features of substantia nigra neurons that project to the thalamus, superior colliculus and pedunculopontine nucleus in the monkey. Neuroscience. 1982;7(10):2377-88.

91. McKernan RM, Whiting PJ. Which GABAA-receptor subtypes really occur in the brain? Trends Neurosci. 1996;19(4):139-43.

92. Tan KR, Brown M, Labouebe G, Yvon C, Creton C, Fritschy JM, Rudolph $U$, Luscher C. Neural bases for addictive properties of benzodiazepines. Nature. 2010;463(7282):769-74.

93. Yee BK, Keist R, von Boehmer L, Studer R, Benke D, Hagenbuch N, Dong Y, Malenka RC, Fritschy JM, Bluethmann H, Feldon J, Mohler H, Rudolph U. A schizophrenia-related sensorimotor deficit links alpha 3-containing GABAA receptors to a dopamine hyperfunction. Proc Natl Acad Sci USA. 2005;102(47):17154-9.

94. Gill KM, Lodge DJ, Cook JM, Aras S, Grace AA. A novel a5GABA(A) R-positive allosteric modulator reverses hyperactivation of the dopamine system in the MAM model of schizophrenia. Neuropsychopharmacology. 2011;36(9):1903-11.

95. Savić MM, Majumder S, Huang S, Edwankar RV, Furtmüller R, Joksimović S, Clayton T Sr, Ramerstorfer J, Milinković MM, Roth BL, Sieghart W, Cook JM. Novel positive allosteric modulators of GABAA receptors: do subtle differences in activity at alpha1 plus alpha5 versus alpha2 plus alpha3 subunits account for dissimilarities in behavioral effects in rats? Prog Neuropsychopharmacol Biol Psychiatry. 2010;34(2):376-86.

\section{Publisher's Note}

Springer Nature remains neutral with regard to jurisdictional claims in published maps and institutional affiliations. 